\title{
Non-B DNA Secondary Structures and Their Resolution by RecQ Helicases
}

\author{
Sudha Sharma \\ Department of Biochemistry and Molecular Biology, College of Medicine, Howard University, 520 W Street, NW, \\ Suite 3424A, Washington, DC 20059, USA \\ Correspondence should be addressed to Sudha Sharma, sudha.sharma@howard.edu
}

Received 25 May 2011; Accepted 25 July 2011

Academic Editor: Souvik Maiti

Copyright (c) 2011 Sudha Sharma. This is an open access article distributed under the Creative Commons Attribution License, which permits unrestricted use, distribution, and reproduction in any medium, provided the original work is properly cited.

In addition to the canonical B-form structure first described by Watson and Crick, DNA can adopt a number of alternative structures. These non-B-form DNA secondary structures form spontaneously on tracts of repeat sequences that are abundant in genomes. In addition, structured forms of DNA with intrastrand pairing may arise on single-stranded DNA produced transiently during various cellular processes. Such secondary structures have a range of biological functions but also induce genetic instability. Increasing evidence suggests that genomic instabilities induced by non-B DNA secondary structures result in predisposition to diseases. Secondary DNA structures also represent a new class of molecular targets for DNA-interactive compounds that might be useful for targeting telomeres and transcriptional control. The equilibrium between the duplex DNA and formation of multistranded non-B-form structures is partly dependent upon the helicases that unwind (resolve) these alternate DNA structures. With special focus on tetraplex, triplex, and cruciform, this paper summarizes the incidence of non-B DNA structures and their association with genomic instability and emphasizes the roles of RecQ-like DNA helicases in genome maintenance by resolution of DNA secondary structures. In future, RecQ helicases are anticipated to be additional molecular targets for cancer chemotherapeutics.

\section{Introduction}

Structure of the right-handed B-form DNA has been known since 1953 [1]. Instead of being a conformationally homogenous molecule, DNA has the capability of adopting several types of conformations as dictated by its sequence [2]. As early as 1957, association of ribonucleic poly-A and poly- $U$ polymers into three-stranded complexes was revealed using sedimentation coefficient and optical absorption measurements [3]. It was later shown by atomic resolution singlecrystal X-ray diffraction analysis that the DNA hexamer

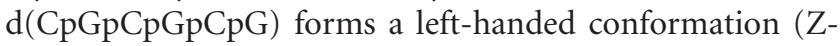
DNA) with altered helical parameters relative to the righthanded B-form [4]. This was followed by the identification of cruciform structures formed by inverted repeats $[5,6]$. Finally, guanine-rich motifs in DNA were discovered to form parallel four-stranded complexes called tetraplex, Gquadruplex, or G4 DNA [7]. More than ten different DNA conformations have now been discovered [8], and these are often referred to as secondary structures, alternative DNA, or non-B DNA. A non-B database has been developed for prediction of alternative DNA structures including Z-DNA motifs, quadruplex-forming motifs, inverted repeats, mirror repeats and direct repeats, and their associated subsets of cruciforms, triplex, and slipped structures, respectively [9].

Non-B DNA structures are functional genomic elements that play a variety of roles in the cell [10]. These include gene function and regulation [11], immune response [12], telomere maintenance [13], recombination [14], antigenic variation in human pathogens [15], and the generation of genomic diversity [16]. The DNA secondary structures are suggested to be involved in regulation at both transcriptional and translational levels; however, when the subtle balance between the replication, transcriptional, and repair machinery is impaired, these secondary structures may induce genetic instability. Alternate structure-forming sequences are known to be unstable and represent hotspots for deletion or recombination in bacteria, yeast, and mammals [17-20]. This genetic instability has generally been related to DNA replication because non-B structures cause DNA polymerase 
pausing in vitro and replication fork pausing in vivo [21]. Slow replication was observed in an inverted repeat sequence in Escherichia coli [22], and inverted repeats lead to deletions or chromosomal rearrangements more frequently in yeast that are deficient in DNA polymerase activity $[23,24]$. Slow progression of the replication fork could facilitate formation of secondary structures at long tracts of single-stranded DNA in the lagging-strand template [25]. These secondary structures pose obstacle to replication fork progression causing fork arrest and/or collapse ultimately leading to double-strand breaks (DSBs) and genome rearrangements $[26,27]$. The formation of alternative DNA structures can also activate nucleotide excision and SOS pathways resulting in segments of single-stranded DNA (ssDNA) [28]. Such ssDNA regions can be converted to DSBs during replication and lead to mutations through mechanisms such as homologous recombination or nonhomologous end joining [29]. Conditions that favor the structural transitions from B-DNA to non-B DNA lead to genetic instability in model systems [27]. Alternative structure-mediated mutagenesis has been implicated in the incidence of gross rearrangements and deletions as well as point mutations [30-32]. There is significant circumstantial evidence for the involvement of DNA secondary structures in association with genetic instability leading to human disease $[33,34]$.

The vastness of mutagenic capability would be predicted to reduce the prevalence of secondary structure-forming tracts in genomes; however they are abundant and often enriched in the regulatory regions of genes [9]. With such an array of challenging sequence elements, it is evident that cells have developed the capacity for controlling the potential of these sequences for genome destabilization. Among several elucidated mechanisms to resolve secondary DNA structures, RecQ helicases represent an important class of enzymatic activities that are utilized to counteract such challenge to genomic stability.

\section{RecQ Helicases}

The RecQ family represents one of the most highly conserved groups of DNA helicases [35-39]. Bacteria and budding yeast have one RecQ homolog, RecQ and SGS1, respectively. The RecQ helicase family has 5 homologs in the human genome: RECQ1, WRN, BLM, RecQ4, and RecQ5 3 (Figure 1). RecQ helicases share a centrally located helicase domain that couples nucleotide hydrolysis to DNA unwinding and defines the RecQ family. Many, but not all, RecQ helicases contain additional conserved RQC (RecQ C-terminal) and HRDC (helicase and RNaseD C-terminal) domains, which are implicated in protein interactions $[40,41]$ and DNA binding [42]. Eukaryotic RecQ helicases have, in addition, further $\mathrm{N}$ - and C-terminal extensions that are involved in protein-protein interactions and postulated to lend unique functional characteristics to each helicase [43, 44]. Certain RecQ homologues also have strongly acidic regions that have been shown to mediate interaction with single-strand DNAbinding proteins such as RPA [37]. Furthermore, nuclear localization signal (NLS) has been identified for several RecQ proteins (Figure 1) [37].

RecQ helicases unwind DNA duplex with $3^{\prime}-5^{\prime}$ polarity in a reaction that is dependent of NTP hydrolysis [37]. Curiously, several RecQ proteins have been demonstrated to also have the ability to promote annealing of complementary strands in a reaction that is inhibited by the presence of ATP [37]. It was confirmed that ATP binding to the protein modulates oligomeric state of RECQ1 and regulates these apparently conflicting biochemical activities [45, 46].

RecQ helicases are remarkable among all DNA helicases for two primary reasons. First, in addition to unwinding duplex DNA, they are capable of unwinding a variety of DNA substrates containing noncanonical structures including forked duplexes, displacement loops (D-loops; an intermediate in homologous recombination reactions), triple helices, 3- or 4-way junctions, and G-quadruplex DNA [37, 47]. In fact, in many instances, they prefer these substrates to standard duplex DNA. Second, germline mutations in three human RecQ helicase homologs WRN, BLM, and RECQ4, which are located on chromosomes 8p-12, 15q26.1 , and $8 \mathrm{q}-24.3$, respectively, give rise to rare genetic disorders of Werner, Bloom, and Rothmund-Thomson/ RAPADILINO/Baller-Gerold syndromes, respectively, all of which are characterized by chromosomal instability and predisposition to cancer [48-51]. Distinct clinical features of these disorders indicate that human RecQ homologs perform unique cellular functions. Cellular studies point to critical requirement of RECQ1 and $\operatorname{RecQ} 5 \beta[52,53]$, but defects in these have not been associated with a human disease yet. As reviewed in next sections, collective biochemical, cellular, and genetic findings signify a pivotal role of RecQ helicases in resolution of non-B DNA structures and genome maintenance.

\section{Prevalence, Consequences, and Unraveling of Non-B Secondary DNA Structures}

Genomic maintenance entails highly regulated interaction of intrinsic factors such as the nature of sequence or the action of DNA replication and repair proteins and extrinsic factors such as environmental mutagens. Repetitive sequences in the genomes have the propensity to form complex secondary structures which could lead to diverse types of genomic instability. One of the common mechanisms of alternative structure-induced instability is obstruction of replication fork progression leading to fork stalling and/or collapse [54]. RecQ helicases are proposed as genome caretakers and guardians of DNA replication forks [55]. The following sections summarize impact of certain specific non-B DNA structures on genomic stability and review the roles of RecQ helicases in resolving these structures.

\subsection{Cruciforms}

3.1.1. Cruciform DNA Structures and Their Occurrence in Genomes. A cruciform structure is formed by intrastrand base pairing of inverted repeat sequences and is characterized 

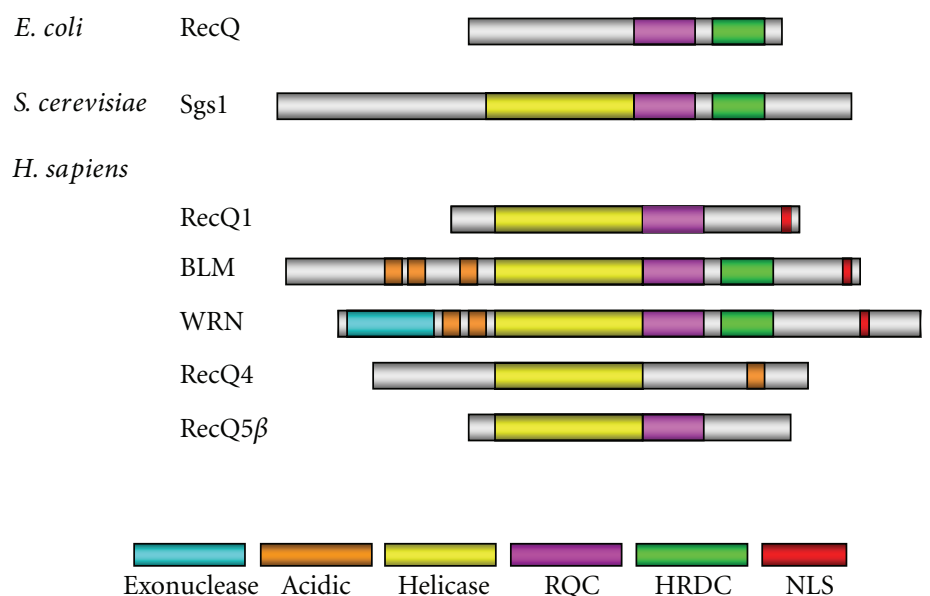

FIgURE 1: The RecQ helicase family. Proteins are aligned by their conserved helicase domain. Conserved domains and motifs in each group are shown by different colors as depicted at the bottom.

by the presence of a four-way junction in which two of the branches are hairpin structures formed on each strand of the inverted repeat [5] (Figure 2(a)). The bases located between the inverted repeats do not self-pair and instead form the apical loops of the hairpins; however the overall structure is stabilized by the free energy of negative supercoiling [56]. Cruciform is structurally similar to a Holliday Junction (HJ) recombination intermediate [57]. In fact, cruciform structures formed by extrusion of an inverted repeat sequence in supercoiled plasmids have been extensively used to study the mechanistic properties of $\mathrm{HJ}$ resolving enzymes [58, 59].

The existence of cruciforms has been demonstrated in vitro [60] and in vivo [61-63]. Cruciform structures have been reported in the genome of E. coli [64] as well as mammalian cells [63]. Cruciform-forming inverted repeat sequences have been found at the operator and transcription termination regions [65], as well as at the replication origin region $[63,66]$. The distribution of such sequences often overlaps with chromosomal regions prone to gross rearrangements [67]. Because cruciform structures are energetically unfavorable, they are thought to form transiently in vivo as stable structures. The action of cellular factors such as junction specific nucleases, binding proteins, and DNA helicases is suggested to affect the equilibrium and the rate of formation of cruciform structures in vivo [68].

3.1.2. Cruciforms and Genomic Instability. Palindromes, a specific type of inverted repeat separated by only very few base pairs, are poorly tolerated in E. coli cells and are underrepresented in the $S$. cerevisiae and human genomes $[69,70]$ presumably due to their tendency to form hairpin and cruciform structures, which could be recognized and cleaved by a nuclease [71] or could affect or slow down DNA replication [72]. Cruciform structures are found in mutagenic hotspots, and their presence has been suggested to be etiologic in causing rearrangements and chromosomal instability in humans $[2,73,74]$. The AT-rich palindromic repeats involved in the recurrent $t(11 ; 22)$ constitutional translocation favor adopting a cruciform structure in vitro and involve frequent DSBs $[75,76]$. Direct Alu repeats artificially inserted in an inverted orientation in the yeast genome undergo DSBs and enter a break-fusion cycle resulting in dicentric chromosomes [77]. It has been proposed that the break might be caused by a cruciform-specific resolution activity similar to $\mathrm{HJ}$ resolvase, which generally is thought to act on intermediates produced through homologous recombination in the repair of DSBs or stalled replication [67]. However, recent studies show that nearby inverted repeats in budding and fission yeasts recombine spontaneously and frequently to form dicentric and acentric chromosomes independent of DSB formation, possibly by a replication mechanism involving template switching $[78,79]$.

3.1.3. Cruciform Resolvases. Four-way DNA joint molecules, termed HJs, are key intermediates in recombination [80]. Proteins with the enzymatic ability to cleave synthetic HJs in vitro have been termed HJ "resolvases," and these DNA junction-resolving enzymes exhibit considerable selectivity for the structure of their substrates [81]. E coli RuvC and its associated proteins RuvA and RuvB constitute the archetypal resolvase system [82]. RuvC is a dimeric protein that promotes $\mathrm{HJ}$ resolution by introducing a pair of symmetrically related nicks in two diametrically opposed strands across the junction point [82]. Ongoing search for the eukaryotic equivalent of bacterial RuvC $\mathrm{HJ}$ resolvase has led to the discovery of a number of DNA endonucleases, including Mus81-Mms4/EME1 [83], Slx-Slx4/BTBD12/MUS312 [8486], XPF-ERCC1 [87], and Yen1/GEN1 [88, 89]. Furthermore, MUS81-EME1 also forms part of a larger nuclease complex containing SLX1-SLX4 and XPF-ERCC1 raising the possibility that these nucleases cooperate to process HJs [81]. Thus, it appears that eukaryotes possess alternative, and mechanistically varied, ways to process HJs, perhaps reflecting the critical importance of this step for cell viability and mutation avoidance. 


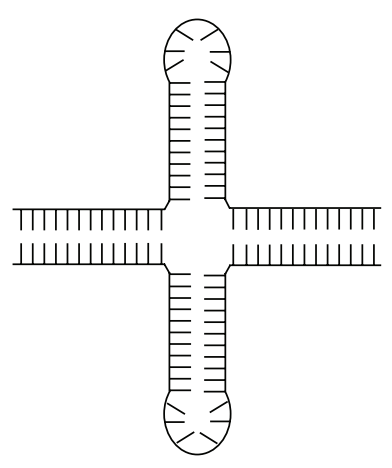

(a)

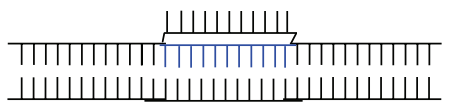

(b)

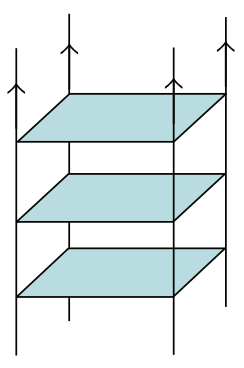

(d)

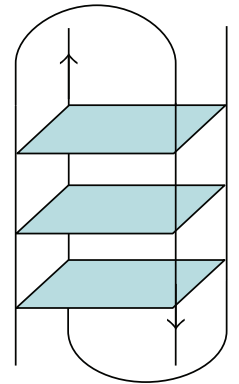

(e)

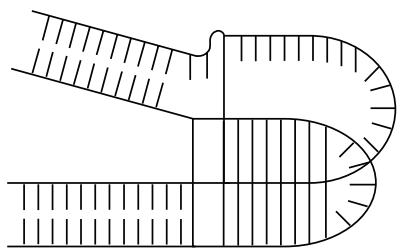

(c)

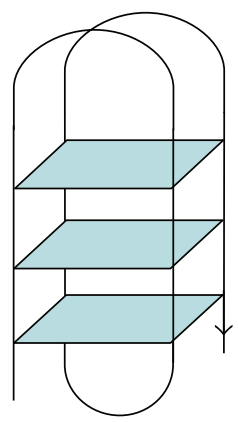

(f)

FIGURE 2: Schematic representation of certain non-B-form DNA structures. DNA can assume various alternate conformations depending upon the sequences. (a) Cruciform structures are formed at inverted repeats and also as intermediates of homologous recombination pathway, (b) Intermolecular triplex are formed by a triplex forming oligonucleotide (TFO, shown in blue) which binds to the purine-rich strand of the target duplex through the major groove. (c) Intramolecular triplex DNA structures can form at homopurine-homopyrimidine sequences with mirror symmetry, where a single-stranded region can bind in the major groove of the underlying DNA duplex to form a three-stranded helix. (d) G4 DNA is formed via parallel arrangement of four G-rich DNA strands; green boxes represent four guanine bases in planar arrangement via Hoogsteen base pairing. (e) Intermolecular G4 conformation is formed by DNA sequences with G-rich repeats forming hairpins that dimerize to stabilize bimolecular structure. (f) Intramolecular G4 DNA (or fold-over G quadruplex) is formed by single DNA strand with either four G-rich repeats or longer G tract that can fold upon themselves to form the G4 structure.

3.1.4. Metabolism of Cruciform-Like Structures by RecQ Helicases. Cellular and biochemical studies have established that RecQ helicases are vital in the metabolism of cruciformlike structures [90]. Loss of SGS1 in S. cerevisiae results in the accumulation of HR-dependent replication intermediates that resemble HJs [91]. In humans, DNA processing defects during replication and/or recombination have been suggested to contribute to the molecular pathology of Werner and Bloom syndromes [92]. Werner syndrome cells fail to resolve recombination intermediates [93], and the expression of wild-type WRN protein or RusA, a bacterial enzyme that cleaves four-way junctions, was both shown to rescue the WRN recombination defect and to improve cell survival following DNA damage [94]. Cytogenetic phenotype of elevated sister chromatid exchanges (SCEs) in Bloom syndrome cells has suggested hyperrecombination or aberrant resolution of DNA recombination intermediates in the absence of active BLM protein [95]. Thus, a potential role for both WRN and BLM would be to prevent DNA structures including $\mathrm{HJ}$ that arise at blocked or collapsed replication forks from being processed into mature recombinants [55].

Indeed, RecQ helicases preferentially resolve 4-way HJs which are formally analogous to cruciform structures [37]. Several RecQ helicase proteins, including human BLM, WRN, RECQ5, and RECQ1, and the yeast homolog SGS1 were shown to selectively bind $\mathrm{HJ}$ structures and to promote ATP-dependent branch migration in vitro [44, 45, 96-99]. Furthermore, BLM [97], WRN [96], RECQ5 [44], and RECQ1 [100] are capable of branch-migrating HJs over several kilobases which is remarkable given that these helicases normally display poor processivity in the absence of RPA [37]. The bacterial HJ core recognition protein RuvA inhibits 
HJ branch migration by BLM, WRN, RECQ1 or RECQ5 $\beta$ suggesting that these RecQ helicases specifically recognize the HJ core where they initiate unwinding [37]. It is conceivable that RecQ helicases may promote branch migration with a mechanism similar to the oligomeric RuvAB branch migration motor wherein two RuvA tetramers bind the junction and promote the loading of two RuvB hexamers on the two arms of the junction [101]. This notion is supported by the fact that BLM, WRN, and RECQ1 form oligomeric structures in solution [102]. The WRN protein binds HJ as an oligomer [103], and an N-terminal fragment of BLM is known to form hexamers and dodecamers [104]. Remarkably, the Nterminal region (residues 1-56) of RECQ1 was found to be essential for both oligomerization and $\mathrm{HJ}$ resolution activity [105].

Slipped strand hairpins or cruciforms with singlestranded regions are also formed at tracts of trinucleotide repeats during replication and stall replication forks [10]. A structure-specific nuclease, Flap endonuclease 1 (FEN-1), has been implicated in resolution of such structures $[54,106$, 107]. The nuclease activity of FEN-1 is robustly stimulated by physical interaction with WRN $[108,109]$. WRN and FEN1 directly interact at the sites of arrested replication forks suggesting that the formation of a functional FEN-1/WRN complex is important for resolving stalled DNA replication forks [110]. Cleavage of an $\mathrm{HJ}$ intermediate of fork regression by FEN-1 requires WRN branch fork migration [110]; WRN helicase activity initiating from the $\mathrm{HJ}$ core provides a suitable DNA molecule with a free $5^{\prime}$ ssDNA end on which FEN1 can load to ultimately catalyze structure-specific cleavage of the unwound 5' ssDNA arm [111]. However, stimulation of FEN-1 is mediated by direct protein-protein interaction but does not require WRN catalytic activity $[108,112]$. In fact, expression of a conserved noncatalytic C-terminal domain of WRN necessary and sufficient for the physical and functional interaction with FEN-1 is sufficient to rescue the yeast dna21 mutant phenotypes [113]. The conserved C-terminal in BLM was subsequently also found to mediate a physical and functional interaction with FEN-1 [109], and the phenotypes of yeast dna2 mutants can be rescued by expression of BLM [114]. Importantly, BLM stimulated FEN-1 cleavage of foldback flaps, bubbles, or triplet repeats in a helicasedependent manner $[115,116]$. Thus, WRN and BLM helicases likely act as very effective remover of structures that inhibit FEN-1 and thereby prevent duplications, expansions, and other genome disruption [111].

Cruciform metabolism is also among critical functions of certain RecQ family helicases that are mediated by the species-specific interaction with topoisomerase III homologs [90]; the Rmil protein serves as an additional component of the heterotrimeric functional complex [117]. The major role of the concerted helicase-topoisomerase complex is to catenate or decatenate dsDNA, resulting in the resolution or "dissolution" of double HJs [118, 119]. Double HJs are shown to exist in vivo and are thought to arise when both ends of a DSB invade a homologous sequence at the final steps of homologous recombination $[120,121]$. Human and Drosophila BLM proteins, but not other RecQ helicases, together with topoisomerase III $\alpha$, have the ability to catalyze double $\mathrm{HJ}$ dissolution on model DNA substrates in a reaction that requires BLM-mediated ATP hydrolysis and the active-site tyrosine residue of topoisomerase III $\alpha$ [118, 122]. BLAP75/RMI promotes BLM-dependent dissolution reaction by recruiting topoisomerase III $\alpha$ to the double $\mathrm{HJ}$ $[123,124]$. Notably, this functional interaction is highly specific, as the BLAP-75 topoisomerase IlIa pair has no effect on either WRN or E. coli RecQ helicase activity, and E. coli Top3 cannot substitute for topoisomerase III $\alpha$ in the enhancement of the BLM helicase activity [125]. Dissolution of $\mathrm{dHJs}$ in S. cerevisiae is performed by the SGS1-Top3Rmil complex [126]. Recent data are consistent with SGS1 and Top3 acting together in vivo because cells lacking SGS1 or Top3 exhibited persistent HJ-containing DNA structures following exposure to DNA damage [127].

Collectively, RecQ helicases constitute a remarkable group of enzymes that promote resolution of HJs via nonresolvase mechanisms, and this is believed to be one of their critical functions in genome maintenance.

\subsection{Triplex}

3.2.1. Triplex Structures and Their Occurrence in Genomes. Naturally occurring homopurine/homopyrimidine sequences can fold into triplex configuration by binding a third strand of DNA or RNA in the major groove of Watson-Crick duplex DNA through Hoogsteen or reversed Hoogsteen hydrogen bonds [128] (Figure 2(c)). Intermolecular triplexes are formed when the triplex-forming strand originates from a second DNA molecule, for example, triplex-forming oligonucleotides (TFOs) [128] (Figure 2(b)). Intramolecular triplexes are the major elements of H-DNAs in which the third strand is provided by one of the strands of the same duplex DNA molecule at homopurine:homopyrimidine sequences with mirror symmetry [129]. Unfavourable charge repulsion between the three negatively charged DNA strands contributes to the low stability of triplexes under physiological conditions. At physiological $\mathrm{pH}$, triplex formation usually involves a purine-rich third strand that is antiparallel to the complementary strand and is stabilized by negative supercoiling, modification with phosphorothioate groups, or polyvalent cations such as $\mathrm{Mg}^{2+}$ or polyamines such as spermine and spermidine [129].

Triplexes have been shown to exist in chromosomes and nuclei, and the existence of H-DNA structures has been evidenced both in vitro and in vivo [130]. Triplex formation in vivo is supported by the identification of mammalian proteins that bind specifically to them $[131,132]$ and to the polypyrimidine [133] and polypurine single strands [18]. H-DNA conformations have been identified in vivo by using triplex-specific monoclonal antibodies [134, 135] and fluorescent "in situ nondenaturing" hybridization [136]. The presence of an H-DNA conformation in vitro has been demonstrated in constructs containing the sequences of interest from E. coli and mammalian genomic DNA or by using chemicals that modify nucleotides specifically in single-stranded DNA or double-stranded DNA [137, 138]. The sequence-specific DNA recognition and binding 
characteristics of synthetic TFOs have been extensively studied because of their potential applications in genome modification and therapy [139]. Most annotated genes in both the mouse and human genomes are predicted to contain at least one unique potential TFO binding site [140]. Similarly, naturally occurring sequences capable of adopting $\mathrm{H}$-DNA structures are very abundant in mammalian cells ( $\sim 1$ in every $50,000 \mathrm{bp}$ in humans) $[129,141]$. Majority of polypurine-polypyrimidine sequences are located in introns, promoters and $5^{\prime}$ or $3^{\prime}$ untranslated regions and are enriched in genes involved in cell signaling and cell communication [142]. Importantly, H-DNA structure-forming sequences are found flanking protooncogenes [143, 144].

3.2.2. Triplex and Genomic Instability. Naturally occurring triplexes are sources of genomic instability, and TFO can induce targeted mutagenesis, recombination, or DNA repair, and can inhibit proliferation and induce apoptosis in cultured cells $[14,31]$. Genomic instability of human DNA sequences that can form triplexes is associated with the etiology of several diseases including neurological disorders [34]. For example, the triplex-forming potential of a (GAA) repeat has been correlated with the genomic instability and reduced frataxin gene expression in Friedreich's ataxia, a triplet repeat disorder [145]. The repeated sequence was shown to inhibit DNA polymerization in vitro and progression of replication forks in vivo suggesting that the triplex formation by the Friedreich's ataxia (GAA) repeat inhibits DNA replication [146, 147]. In addition to posing block to replication progression [148], naturally occurring triplex-forming sequences have been shown to interfere with transcription [144]. Many breakpoints on the translocated $c-m y c$ gene in Burkitt's lymphoma and $\mathrm{t}(12 ; 15) \mathrm{BALB} / \mathrm{c}$ plasmacytomas are clustered around the H-DNA-forming sequences in the promoter regions [149]. Indeed, the naturally occurring $\mathrm{H}$-DNA structure-forming sequence from the human $c-M Y C$ gene was shown to induce DSBs within these sequences in mammalian cells [32] and cause genomic instability in mice [149]. Collectively, these studies imply that the triplex structures result in fragile sites or mutation hotspots causing DSBs and subsequent translocation of the gene [129]. As part of the mechanisms whereby cells prevent the deleterious effects of alternate DNA structures, triplex formation in vivo is likely to be at least partly inhibited by destabilizing proteins or helicases.

3.2.3. Triplex Unwinding by RecQ Helicases. Triplex-forming sequences have been demonstrated to block replication in vitro [148]. Purified recombinant E. coli RecQ protein partially alleviates triplex formation and facilitates fork progression through triplex-forming DNA in vitro; loss of RecQ significantly increases the mutations caused by triplexforming DNA in vivo [150]. RecQ-deficient E. coli utilize RecG helicase for fork regression upon encountering triplex structures and thereby restart replication [150]. A RecG equivalent in human is not identified yet, but human BLM and WRN helicases can unwind a DNA triple helix [151] and also catalyze fork regression [152]. In vitro studies with triple helices formed by a pyrimidine motif third strand demonstrated that WRN and BLM catalyze triplex unwinding in nucleoside triphosphate hydrolysis-dependent reaction and require a free $3^{\prime}$-ssDNA overhang attached to the third strand [151]. Triplex unwinding by BLM and WRN does not require a single strand:double strand fork at the junction of the third strand and the triplex [151] indicating that the unwinding is promoted by inherent structural elements of the triplex substrate; this might also be facilitated by the oligomeric structures of these helicases [102]. More recently it was demonstrated that DHX9 (nuclear DNA helicase II (NDH II) or RNA helicase A (RHA)) protein, a superfamily 2 helicase, preferentially unwinds intermolecular triplex DNA substrates in vitro with a specific $3^{\prime}-5^{\prime}$ polarity with respect to the displaced third strand (similar to BLM and WRN helicase); this activity required a $3^{\prime}$-ssDNA overhang on the third strand and was dependent on ATP hydrolysis [153]. In contrast, a $5^{\prime}$-ssDNA overhang on the triplex-forming oligonucleotide is required to unwind the third strand of the triplex structure by FANCJ, a superfamily 2 helicase that unwinds DNA in the $5^{\prime}-3^{\prime}$ direction [154]. This is consistent with the observations that FANCJ requires a preexisting $5^{\prime}$-ssDNA to unwind conventional B-form duplex DNA substrates [155] and G-quadruplex DNA substrates [156]. Triplex unwinding by other human RecQ proteins has not been reported yet; however, examination of individual RecQ homolog might reveal differential preference for non-B DNA structures [105].

Identification and characterization of triplex unwinding helicases have signified the critical importance of triplex resolution for genomic stability. This is highlighted by the fact that mutations in WRN, BLM, FANCJ lead to genomic instability and certain cancer in humans [157], whereas homozygous DHX9 knockout mice are embryonic lethal [158]. Cellular DNA metabolic processes involve transient formation of ssDNA which can possibly interact with other strands to form secondary and tertiary structures [159]. If triplexes are not resolved, they can potentially interfere with processes such as DNA replication, recombination, and repair [129]. Further investigations to uncover the roles of helicases in resolving triplex DNA structures are necessary for understanding the cellular mechanism(s) for genome stability maintenance.

\subsection{G4 DNA}

3.3.1. G4 DNA Structures and Their Occurrence in Genomes. G-quadruplexes form in vitro in guanine-rich sequences that contain four tracts of at least three guanines separated by other bases and are stabilized by G-quartets [160]. The Gquartets arise from the association of four guanines into a cyclic Hoogsten hydrogen-bonding arrangement in which each guanine base makes two hydrogen bonds with its neighbor using different hydrogen-bonding positions to the canonical Watson-Crick base pairing. The planar G-quartets stack on top of each other, giving rise to four-stranded helical structures (Figure 2(d)). These structures, called G-tetraplex, G-quadruplex, or G4 DNA, may involve intramolecular or 
intermolecular interactions, and the phosphodiester backbones of the four participating strands may be in parallel or antiparallel orientation [161] (Figures 2(e) and 2(f)). The formation of G4 structures is strongly dependent on monovalent cations such as $\mathrm{K}^{+}$and $\mathrm{Na}^{+}$and, hence, physiological buffer conditions favor their formation, and it has been suggested that G4 DNA may be routinely assembled and disassembled within cells [162].

The human genome contains nearly 376000 distinct sites with the potential to form G4 DNA $[163,164]$, and the evidence for in vivo formation of G4 DNA has emerged in recent years [165]. Notably, G4 DNA has been observed by electron microscopy from transcribed human G-rich DNA arrays in bacteria [166] and by immunochemistry at the end of the ciliate Oxytricha telomeres [167]. The G-rich chromosomal domains predicted to form G4 DNA include four classes of repetitive regions: telomeres, rDNA, immunoglobulin heavy chain switch region, and G-rich minisatellites [168]. Replication, recombination, transcription, and telomeric DNA elongation involve steps in which two strands of duplex DNA can be unwound transiently, providing an opportunity for the G-rich strand to form quadruplex structures during these DNA metabolic events [165]. Formation of G4 DNA modulates key cellular processes such as immunoglobulin gene rearrangement, promoter activation, and telomere maintenance [169].

3.3.2. G4 DNA and Genomic Instability. A direct link between potential G4-forming sequences and genomic instability has been provided by genetic studies in model organisms. DOG-1 (deletions of guanine-rich DNA), an ortholog of mammalian FANCJ helicase, is essential for the stability of G-tracts in the genome of C. elegans $[170,171]$. Worms defective in DOG-1 accumulate deletions in regions of the genome containing long G-tracts [171] whereas the introduction of a G-quadruplex-forming DNA sequence into C. elegans is highly mutagenic and is removed from genomes lacking DOG-1 [170]. FANCJ is one of the 13 known genes which lead to Fanconi anemia, and cells from patients lacking functional FANCJ accumulate large genomic DNA deletions that map to potential G4-forming sequences [172]. Moreover, FANCJ preferentially unwinds G quadruplexes over other DNA substrates in vitro suggesting that the FANCJ helicase, like DOG-1, functions in resolving potential replication impediments caused by DNA Gquadruplexes [156]. The RTEL (regulator of telomere length) helicase, another DOG-1 homolog, has a very clear role at telomeres in mice, and RTEL-deficient embryonic stem cells exhibit chromosome-end fusions lacking detectable telomere signals [173]. It is suggested that G-quadruplexes impose a structural barrier to DNA replication and various nucleic acid processing enzymes and are a potential source of genetic instability if not resolved. Identification of several DNA helicases that efficiently unwind and disrupt G4 DNA indicates that eukaryotic cells possess the mechanism for resolution of G4 DNA structures.

3.3.3. Resolution of G4 DNA by RecQ Helicases. RecQ family members are prominent in that they preferentially unwind tetraplex DNA [37]. The E. coli RecQ [174], yeast SGS1 [175], and human WRN [176] and BLM [177] proteins have been demonstrated to melt synthetic G4 DNA constructs. Both SGS1 and BLM unwind G4 DNA with at least 15-fold preference relative to duplex substrates $[175,178,179]$ and HJ structures [178]. This substrate preference correlates with the binding affinity and maps to the conserved RQC region of the RecQ proteins [41]. The G4 DNA unwinding activity is proposed to contribute in the maintenance of two G-rich genomic domains, rDNA and telomeres. SGS1 is required for recombination-mediated lengthening of telomeres in telomerase-deficient S. cerevisiae [180-182]. Furthermore, SGS1-deficient cells are characterized by nucleolar fragmentation and production of rDNA circles suggesting a role of SGS1 in rDNA metabolism $[183,184]$. A possible role of WRN in rDNA metabolism is indicated by the fact that a significant fraction of WRN is nucleolar [185]. Notably, cells from Werner syndrome patients show premature senescence and accelerated rates of telomere shortening [186]. WRN helicase was shown to be necessary for preventing dramatic telomere loss during lagging-strand replication of the G-rich strand and the consequent accumulation of chromosome aberrations such as chromosome fusions [187]. Consistent with a role in telomere maintenance, the WRN helicase is localized to telomeres, possibly via its interaction with TRF2 which also binds BLM $[188,189]$.

By resolving the tetraplex and other non-B DNA structures, RecQ proteins might clear the way for DNA polymerase during replication or repair synthesis. In support of this hypothesis, Kamath-Loeb et al. demonstrated that physical association of DNA polymerase $\delta$ with WRN enables unwinding of tetraplex (and hairpin) structures by the helicase and allows polymerase to pass through the roadblock $[190,191]$. WRN was also shown to physically interact with p50 subunit of human pol $\delta$ which constitutes the active dimeric core of the enzyme with p125 subunit [192]. Thus a possible function of WRN (and presumably other RecQ proteins) might be the recruitment of this polymerase to the complex secondary structures and restoration of stalled DNA synthesis. Indeed, stimulation of DNA polymerase activity of pol $\delta$ by BLM and stimulation of BLM helicase activity by pol $\delta$ have been demonstrated [193]. Cellular phenotypes of genetic mutants and the demonstration of robust G4unwinding activity in vitro support the notion that failure to unwind G4 DNA contributes in part to the genetic instability observed in Bloom and Werner syndrome cells.

Yet, RecQ proteins are not the only helicases known to resolve G4 structures. Besides FANCJ and its orthologs, Pif1 (petite integration frequency 1), a $5^{\prime}-3^{\prime}$ helicase, processes G4-forming sequences in vivo and in vitro [194]. Human Pif1 helicase has been shown to bind and unwind Gquadruplex DNA [195]. In yeast, the involvement of Pif1 in telomere stability has been well established [196], and the association of hPif1 with telomeres and telomerase [197] indicates that hPif1 is a telomere G4 DNA-binding protein. Using genome-wide chromatin immunoprecipitation and Pif1-deficient cells, Zakian group has recently demonstrated that G4 motifs are a significant subset of the in vivo binding sites of the $S$. cerevisiae Pif1, and DNA replication through 
G4 motifs is promoted by the S. cerevisiae Pif1 DNA helicase [198]. The G4 DNA resolving activity of mammalian Pif1 is of questionable significance as such since the Pif1-null mice are normal [199], a contrasting condition with WRN or BLM-deficient cells where genomic instability can be readily detected. It is conceivable that Pif1 activity is normally unnecessary, with sufficient G4 resolvase activity provided by other helicases (e.g., WRN, BLM, and FANCJ). It is possible that a requirement for Pif1 in mammalian cells would be obvious when one or more of these other G4 resolvase systems are compromised.

G4 resolution is, nevertheless, not a common characteristic of all RecQ helicases. Recently, it was demonstrated that RECQ1 does not unwind G-quadruplex substrates [105]. The inability to resolve this particular form of alternate DNA structure distinguishes RECQ1 from WRN, BLM, SGS1, or E. coli RecQ helicases which proficiently unwind a variety of Gquadruplex DNA substrates [45]. Furthermore, the telomere lengths of RECQ1 wild-type, knockout, or heterozygous mouse cells show no significant difference suggesting minimum to no role of RECQ1 in telomere maintenance [200]. However, RECQ1 was purified with human telomeric chromatin specifically in cells that use a recombination mediated pathway known as Alternative Lengthening of Telomeres (ALTs) for telomere maintenance [201]. It is possible that RECQ1 plays indirect role in telomere metabolism via its interacting partners. Supporting this notion, recent evidence suggests that SGS1 regulates processing of telomeres by the 5'-3' exonuclease, EXO1 [202]. Interestingly, RECQ1 and EXO1 exhibit physical and functional interaction in human cells [203]; however, it remains to be tested whether they collaborate in a complex for accurate processing of chromosome ends.

Regardless, it has been demonstrated through various studies that certain RecQ helicases are crucial for the metabolism of G4 DNA structures at specific genome locations such as telomeres and rDNA. Mutant phenotypes in yeast and humans affirm vital importance of this function of RecQ helicases in genome maintenance.

\section{Concluding Remarks and Outlook}

Proficiency of RecQ helicases in unwinding alternate DNA structures has implicated them as roadblock removers for replication fork progression since the DNA sequences that can form unusual, non-B-form structures have been shown to block polymerases in vitro [21]. It has been proposed that at least one function of the RecQ DNA helicases is to prevent aberrant deleterious recombinogenic pathways when replication is perturbed by DNA damage, alternate DNA structure, or impaired DNA synthesis [204]. The processing of aberrant DNA structures by RecQ helicases is likely to counter their potential toxicity incurred by recombinogenic pathways [205] (Figure 3). The ability of helicases to unwind non-B DNA structures would be expected to increase access to repair and replication proteins. The RecQ helicases work in close coordination with other proteins (e.g., topoisomerases) to resolve various secondary structures.

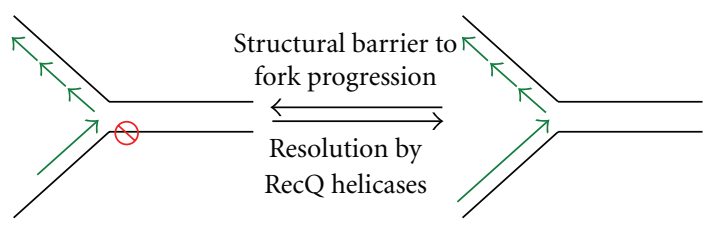

Figure 3: Proposed function of secondary structure resolution by RecQ helicases. Alternate DNA structures (indicated by red symbol) act as natural barrier to replication fork progression and can lead to fork stalling, collapse and ensue recombinogenic processing. Resolution by RecQ helicases is proposed to serve as roadblock remover for smooth progression of replication fork to avoid mutagenesis and/or genome rearrangements.

Associations of RecQ helicases with proteins critical for various steps of DNA replication and repair [37] suggest that RecQ helicases might cooperate with them to ensure faithful progression of replication forks through natural impediments by non-B DNA structures. It is likely that there is competition between the proteins which promote non-B secondary structure formation and RecQ helicases in vivo. Future studies will uncover how the activities of RecQ-helicases are controlled/regulated (via protein-protein interactions, posttranslational modifications, etc.) for maintaining genomic stability in general and preventing non-B DNA structure-induced instability in particular.

As noted above, RecQ proteins exhibit subtle but noteworthy differences among themselves with respect to their ability to unwind or preference for certain alternate DNA structures. Evidently, current data implies that individual human RecQ homologs are uniquely required to unwind specific DNA structures in vivo. Further investigation is essential to elucidate cellular environment, genomic contexts, and/or protein factors that license a specific RecQ protein to metabolize specific DNA structures in vivo. It is clear that non-B structures both perform physiological roles and potentiate genomic instability. Analyses of the mutation spectrum and genomic rearrangements in RecQdeficient cells will illustrate significance of RecQ helicases in underlying mutational mechanisms associated with non-B DNA structures [206].

An opportunistic aspect of the unique nature of naturally occurring non-B DNA conformations is to use them as potential target for cancer therapy since these sequencespecific structures are proposed to affect gene expression and telomere activation, respectively [207, 208]. Gene expression of oncogenes could be selectively inhibited by using chemicals (drugs) or small molecules targeted to specific nonB DNA conformation present in their regulatory regions [129, 209]; stabilizing the secondary structures would be predicted to prevent access of nucleic acid binding proteins and interfere with critical cellular processes. Considering the demonstrated roles of RecQ helicases in resolving such nonB DNA structures, specific inhibition of RecQ and other non-B resolving helicases via small molecules [210], DNAbinding drugs or gene silencing might be a promising strategy to explore for anticancer therapy [207]. Development of new methodologies to investigate specific functions of non- $B$ 
DNA structures and identification of novel structure-specific DNA helicases involved in resolution of such secondary structures will certainly expand the array of molecular targets available for drug development and therapeutic intervention.

\section{Acknowledgment}

This work is made possible in part by NIH/NCRR Grant 2 G12 RR003048 and NIH/NIGMS Grant 7SC1GM09399902 .

\section{References}

[1] J. D. Watson and F. H. C. Crick, "Molecular structure of nucleic acids: a structure for deoxyribose nucleic acid," Nature, vol. 171, no. 4356, pp. 737-738, 1953.

[2] A. Bacolla and R. D. Wells, "Non-B DNA conformations, genomic rearrangements, and human disease," Journal of Biological Chemistry, vol. 279, no. 46, pp. 47411-47414, 2004.

[3] G. Felsenfeld, D. R. Davies, and A. Rich, "Formation of a three-stranded polynucleotide molecule," Journal of the American Chemical Society, vol. 79, no. 8, pp. 2023-2024, 1957.

[4] A. H. J. Wang, G. J. Quigley, F. J. Kolpak et al., "Molecular structure of a left-handed double helical DNA fragment at atomic resolution," Nature, vol. 282, no. 5740, pp. 680-686, 1979.

[5] D. M. Lilley, "The inverted repeat as a recognizable structural feature in supercoiled DNA molecules," Proceedings of the National Academy of Sciences of the United States of America, vol. 77, no. 11, pp. 6468-6472, 1980.

[6] N. Panayotatos and R. D. Wells, "Cruciform structures in supercoiled DNA," Nature, vol. 289, no. 5797, pp. 466-469, 1981.

[7] D. Sen and W. Gilbert, "Formation of parallel four-stranded complexes by guanine-rich motifs in DNA and its implications for meiosis," Nature, vol. 334, no. 6180, pp. 364-366, 1988.

[8] D. Svozil, J. Kalina, M. Omelka, and B. Schneider, "DNA conformations and their sequence preferences," Nucleic Acids Research, vol. 36, no. 11, pp. 3690-3706, 2008.

[9] R. Z. Cer, K. H. Bruce, U. S. Mudunuri et al., "Non-B DB: a database of predicted non-B DNA-forming motifs in mammalian genomes," Nucleic Acids Research, vol. 39, supplement 1, pp. D383-D391, 2011.

[10] J. Zhao, A. Bacolla, G. Wang, and K. M. Vasquez, "NonB DNA structure-induced genetic instability and evolution," Cellular and Molecular Life Sciences, vol. 67, no. 1, pp. 43-62, 2010.

[11] B. P. Belotserkovskii, R. Liu, S. Tornaletti, M. M. Krasilnikova, S. M. Mirkin, and P. C. Hanawalt, "Mechanisms and implications of transcription blockage by guanine-rich DNA sequences," Proceedings of the National Academy of Sciences of the United States of America, vol. 107, no. 29, pp. 12816$12821,2010$.

[12] D. A. Collier, J. A. Griffin, and R. D. Wells, "Non-B right-handed DNA conformations of homopurine-homopyrimidine sequences in the murine immunoglobulin $\mathrm{C}(\alpha)$ switch region," Journal of Biological Chemistry, vol. 263, no. 15, pp. 7397-7405, 1988.
[13] S. Neidle and G. N. Parkinson, "The structure of telomeric DNA," Current Opinion in Structural Biology, vol. 13, no. 3, pp. 275-283, 2003.

[14] J. Y. Chin, E. B. Schleifman, and P. M. Glazer, "Repair and recombination induced by triple helix DNA," Frontiers in Bioscience, vol. 12, pp. 4288-4297, 2007.

[15] J. T. Meier, M. I. Simon, and A. G. Barbour, "Antigenic variation is associated with DNA rearrangements in a relapsing fever Borrelia," Cell, vol. 41, no. 2, pp. 403-409, 1985.

[16] S. S. Smith, "Evolutionary expansion of structurally complex DNA sequences," Cancer Genomics and Proteomics, vol. 7, no. 4, pp. 207-215, 2010.

[17] G. A. Cromie, C. B. Millar, K. H. Schmidt, and D. R. Leach, "Palindromes as substrates for multiple pathways of recombination in Escherichia coli," Genetics, vol. 154, no. 2, pp. 513-522, 2000.

[18] A. Collick, J. Drew, J. Penberth et al., "Instability of long inverted repeats within mouse transgenes," EMBO Journal, vol. 15 , no. 5, pp. 1163-1171, 1996.

[19] D. A. Gordenin, K. S. Lobachev, N. P. Degtyareva, A. L. Malkova, E. Perkins, and M. A. Resnick, "Inverted DNA repeats: a source of eukaryotic genomic instability," Molecular and Cellular Biology, vol. 13, no. 9, pp. 5315-5322, 1993.

[20] D. Branzei and M. Foiani, "Leaping forks at inverted repeats," Genes and Development, vol. 24, no. 1, pp. 5-9, 2010.

[21] E. V. Mirkin and S. M. Mirkin, "Replication fork stalling at natural impediments," Microbiology and Molecular Biology Reviews, vol. 71, no. 1, pp. 13-35, 2007.

[22] D. R. Leach, "Long DNA palindromes, cruciform structures, genetic instability and secondary structure repair," BioEssays, vol. 16, no. 12, pp. 893-900, 1994.

[23] B. Ruskin and G. R. Fink, "Mutations in POL1 increase the mitotic instability of tandem inverted repeats in Saccharomyces cerevisiae," Genetics, vol. 134, no. 1, pp. 43-56, 1993.

[24] F. J. Lemoine, N. P. Degtyareva, K. Lobachev, and T. D. Petes, "Chromosomal translocations in yeast induced by low levels of DNA polymerase: a model for chromosome fragile sites," Cell, vol. 120, no. 5, pp. 587-598, 2005.

[25] R. R. Sinden, V. I. Hashem, and W. A. Rosche, "DNADirected mutations. Leading and lagging strand specificity," Annals of the New York Academy of Sciences, vol. 870, pp. 173189, 1999.

[26] G. Wang and K. M. Vasquez, "Non-B DNA structure-induced genetic instability," Mutation Research, vol. 598, no. 1-2, pp. 103-119, 2006.

[27] A. Bacolla, M. Wojciechowska, B. Kosmider, J. E. Larson, and R. D. Wells, "The involvement of non-B DNA structures in gross chromosomal rearrangements," DNA Repair, vol. 5, no. 9-10, pp. 1161-1170, 2006.

[28] A. Bacolla, A. Jaworski, T. D. Connors, and R. D. Wells, "PKD1 unusual DNA conformations are recognized by nucleotide excision repair," Journal of Biological Chemistry, vol. 276, no. 21, pp. 18597-18604, 2001.

[29] E. Petermann and T. Helleday, "Pathways of mammalian replication fork restart," Nature Reviews Molecular Cell Biology, vol. 11, no. 10, pp. 683-687, 2010.

[30] A. Bacolla, A. Jaworski, J. E. Larson et al., "Breakpoints of gross deletions coincide with non-B DNA conformations," Proceedings of the National Academy of Sciences of the United States of America, vol. 101, no. 39, pp. 14162-14167, 2004.

[31] G. Wang, M. M. Seidman, and P. M. Glazer, "Mutagenesis in mammalian cells induced by triple helix formation and transcription-coupled repair," Science, vol. 271, no. 5250, pp. 802-805, 1996. 
[32] G. Wang and K. M. Vasquez, "Naturally occurring HDNA-forming sequences are mutagenic in mammalian cells," Proceedings of the National Academy of Sciences of the United States of America, vol. 101, no. 37, pp. 13448-13453, 2004.

[33] R. D. Wells, "Discovery of the role of non-B DNA structures in mutagenesis and human genomic disorders," The Journal of Biological Chemistry, vol. 284, no. 14, pp. 8997-9009, 2009.

[34] A. Bacolla and R. D. Wells, "Non-B DNA conformations as determinants of mutagenesis and human disease," Molecular Carcinogenesis, vol. 48, no. 4, pp. 273-285, 2009.

[35] V. A. Bohr, "Rising from the RecQ-age: the role of human RecQ helicases in genome maintenance," Trends in Biochemical Sciences, vol. 33, no. 12, pp. 609-620, 2008.

[36] I. D. Hickson, "RecQ helicases: caretakers of the genome," Nature Reviews Cancer, vol. 3, no. 3, pp. 169-178, 2003.

[37] S. Sharma, K. M. Doherty, and R. M. Brosh Jr., "Mechanisms of RecQ helicases in pathways of DNA metabolism and maintenance of genomic stability," Biochemical Journal, vol. 398, no. 3, pp. 319-337, 2006.

[38] K. J. Ouyang, L. L. Woo, and N. A. Ellis, "Homologous recombination and maintenance of genome integrity: cancer and aging through the prism of human RecQ helicases," Mechanisms of Ageing and Development, vol. 129, no. 7-8, pp. 425-440, 2008.

[39] J. A. Cobb, L. Bjergbaek, and S. M. Gasser, "RecQ helicases: at the heart of genetic stability," FEBS Letters, vol. 529, no. 1, pp. 43-48, 2002.

[40] J. W. Lee, R. Kusumoto, K. M. Doherty et al., "Modulation of Werner syndrome protein function by a single mutation in the conserved RecQ domain," Journal of Biological Chemistry, vol. 280, no. 47, pp. 39627-39636, 2005.

[41] M. D. Huber, M. L. Duquette, J. C. Shiels, and N. Maizels, "A conserved G4 DNA binding domain in RecQ family helicases," Journal of Molecular Biology, vol. 358, no. 4, pp. 1071-1080, 2006.

[42] D. A. Bernstein and J. L. Keck, "Conferring substrate specificity to DNA helicases: role of the RecQ HRDC domain," Structure, vol. 13, no. 8, pp. 1173-1182, 2005.

[43] L. Wu and I. D. Hickson, "DNA helicases required for homologous recombination and repair of damaged replication forks," Annual Review of Genetics, vol. 40, pp. 279-306, 2006.

[44] P. L. Garcia, Y. Liu, J. Jiricny, S. C. West, and P. Janscak, "Human RECQ51 $\beta$, a protein with DNA helicase and strandannealing activities in a single polypeptide," EMBO Journal, vol. 23, no. 14, pp. 2882-2891, 2004.

[45] S. Sharma, J. A. Sommers, S. Choudhary et al., "Biochemical analysis of the DNA unwinding and strand annealing activities catalyzed by human RECQ1," Journal of Biological Chemistry, vol. 280, no. 30, pp. 28072-28084, 2005.

[46] L. Muzzolini, F. Beuron, A. Patwardhan et al., "Different quaternary structures of human RECQ1 are associated with its dual enzymatic activity," PLoS Biology, vol. 5, no. 2, article e20, 2007.

[47] C. Z. Bachrati and I. D. Hickson, "Analysis of the DNA unwinding activity of RecQ family helicases," Methods in Enzymology, vol. 409, pp. 86-100, 2006.

[48] C. Z. Bachrati and I. D. Hickson, "RecQ helicases: suppressors of tumorigenesis and premature aging," Biochemical Journal, vol. 374, no. 3, pp. 577-606, 2003.

[49] C. E. Yu, J. Oshima, Y. H. Fu et al., "Positional cloning of the Werner's syndrome gene," Science, vol. 272, no. 5259, pp. 258-262, 1996.
[50] N. A. Ellis, J. Groden, T. Z. Ye et al., "The Bloom's syndrome gene product is homologous to RecQ helicases," Cell, vol. 83, no. 4, pp. 655-666, 1995.

[51] S. Kitao, A. Shimamoto, M. Goto et al., "Mutations in RECQL4 cause a subset of cases of Rothmund-Thomson syndrome," Nature Genetics, vol. 22, no. 1, pp. 82-84, 1999.

[52] S. Sharma and R. M. Brosh Jr., "Unique and important consequences of RECQ1 deficiency in mammalian cells," Cell Cycle, vol. 7, no. 8, pp. 989-1000, 2008.

[53] Y. Hu, S. Raynard, M. G. Sehorn et al., "RECQL5/Recq15 helicase regulates homologous recombination and suppresses tumor formation via disruption of Rad51 presynaptic filaments," Genes and Development, vol. 21, no. 23, pp. 30733084, 2007.

[54] R. D. Wells, R. Dere, M. L. Hebert, M. Napierala, and L. S. Son, "Advances in mechanisms of genetic instability related to hereditary neurological diseases," Nucleic Acids Research, vol. 33, no. 12, pp. 3785-3798, 2005.

[55] C. Z. Bachrati and I. D. Hickson, "RecQ helicases: guardian angels of the DNA replication fork," Chromosoma, vol. 117, no. 3, pp. 219-233, 2008.

[56] E. A. Oussatcheva, J. Pavlicek, O. F. Sankey, R. R. Sinden, Y. L. Lyubchenko, and V. N. Potaman, "Influence of global DNA topology on cruciform formation in supercoiled DNA," Journal of Molecular Biology, vol. 338, no. 4, pp. 735-743, 2004.

[57] G. R. Smith, "Meeting DNA palindromes head-to-head," Genes and Development, vol. 22, no. 19, pp. 2612-2620, 2008.

[58] R. R. Sinden and D. E. Pettijohn, "Cruciform transitions in DNA," Journal of Biological Chemistry, vol. 259, no. 10, pp. 6593-6600, 1984.

[59] J. M. Fogg and D. M. Lilley, "Ensuring productive resolution by the junction-resolving enzyme RuvC: large enhancement of the second-strand cleavage rate," Biochemistry, vol. 39, no. 51, pp. 16125-16134, 2000.

[60] K. M. Karrer and J. G. Gall, "The macronuclear ribosomal DNA of Tetrahymena pyriformis is a palindrome," Journal of Molecular Biology, vol. 104, no. 2, pp. 421-453, 1976.

[61] R. R. Sinden, S. S. Broyles, and D. E. Pettijohn, "Perfect palindromic lac operator DNA sequence exists as a stable cruciform structure in supercoiled DNA in vitro but not in vivo," Proceedings of the National Academy of Sciences of the United States of America, vol. 80, no. 7 I, pp. 1797-1801, 1983.

[62] N. Panayotatos and A. Fontaine, "A native cruciform DNA structure probed in bacteria by recombinant T7 endonuclease," Journal of Biological Chemistry, vol. 262, no. 23, pp. 11364-11368, 1987.

[63] M. Zannis-Hadjopoulos, L. Frappier, M. Khoury, and G. B. Price, "Effect of anti-cruciform DNA monoclonal antibodies on DNA replication," EMBO Journal, vol. 7, no. 6, pp. 18371844, 1988

[64] J. A. McClellan, P. Boublikova, E. Palecek, and D. M. Lilley, "Superhelical torsion in cellular DNA responds directly to environmental and genetic factors," Proceedings of the National Academy of Sciences of the United States of America, vol. 87, no. 21, pp. 8373-8377, 1990.

[65] M. Rosenberg and D. Court, "Regulatory sequences involved in the promotion and termination of RNA transcription," Annual Review of Genetics, vol. 13, pp. 319-353, 1979.

[66] D. Lockshon and D. A. Galloway, "Sequence and structural requirements of a herpes simplex viral DNA replication origin," Molecular and Cellular Biology, vol. 8, no. 10, pp. 4018-4027, 1988. 
[67] K. S. Lobachev, A. Rattray, and V. Narayanan, "Hairpinand cruciform-mediated chromosome breakage: causes and consequences in eukaryotic cells," Frontiers in Bioscience, vol. 12, pp. 4208-4220, 2007.

[68] K. Mizuuchi, M. Mizuuchi, and M. Gellert, "Cruciform structures in palindromic DNA are favored by DNA supercoiling," Journal of Molecular Biology, vol. 156, no. 2, pp. 229243, 1982.

[69] K. S. Lobachev, J. E. Stenger, O. G. Kozyreva, J. Jurka, D. A. Gordenin, and M. A. Resnick, "Inverted Alu repeats unstable in yeast are excluded from the human genome," $E M B O$ Journal, vol. 19, no. 14, pp. 3822-3830, 2000.

[70] J. E. Stenger, K. S. Lobachev, D. Gordenin, T. A. Darden, J. Jurka, and M. A. Resnick, "Biased distribution of inverted and direct Alus in the human genome: implications for insertion, exclusion, and genome stability," Genome Research, vol. 11, no. 1, pp. 12-27, 2001.

[71] D. R. Leach and F. W. Stahl, "Viability of $\lambda$ phages carrying a perfect palindrome in the absence of recombination nucleases," Nature, vol. 305, no. 5933, pp. 448-451, 1983.

[72] A. Ahmed and L. Podemski, "Observations on template switching during DNA replication through long inverted repeats," Gene, vol. 223, no. 1-2, pp. 187-194, 1998.

[73] S. C. Raghavan, P. C. Swanson, X. Wu, C. L. Hsieh, and M. R. Lieber, "A non-B-DNA structure at the Bcl-2 major breakpoint region is cleaved by the RAG complex," Nature, vol. 428 , no. 6978 , pp. 88-93, 2004.

[74] H. Kurahashi, H. Inagaki, T. Ohye, H. Kogo, T. Kato, and B. S. Emanuel, "Chromosomal translocations mediated by palindromic DNA," Cell Cycle, vol. 5, no. 12, pp. 1297-1303, 2006.

[75] H. Kurahashi, H. Inagaki, T. Ohye et al., "The constitutional $\mathrm{t}(11 ; 22)$ : implications for a novel mechanism responsible for gross chromosomal rearrangements," Clinical Genetics, vol. 78, no. 4, pp. 299-309, 2010.

[76] H. Kurahashi, H. Inagaki, K. Yamada et al., "Cruciform DNA structure underlies the etiology for palindrome-mediated human chromosomal translocations," Journal of Biological Chemistry, vol. 279, no. 34, pp. 35377-35383, 2004.

[77] K. S. Lobachev, D. A. Gordenin, and M. A. Resnick, "The Mre11 complex is required for repair of hairpincapped double-strand breaks and prevention of chromosome rearrangements," Cell, vol. 108, no. 2, pp. 183-193, 2002.

[78] A. L. Paek, S. Kaochar, H. Jones, A. Elezaby, L. Shanks, and T. Weinert, "Fusion of nearby inverted repeats by a replication-based mechanism leads to formation of dicentric and acentric chromosomes that cause genome instability in budding yeast," Genes and Development, vol. 23, no. 24, pp. 2861-2875, 2009.

[79] K. Mizuno, S. Lambert, G. Baldacci, J. M. Murray, and A. M. Carr, "Nearby inverted repeats fuse to generate acentric and dicentric palindromic chromosomes by a replication template exchange mechanism," Genes and Development, vol. 23, no. 24, pp. 2876-2886, 2009.

[80] J. E. Haber, G. Ira, A. Malkova, and N. Sugawara, "Repairing a double-strand chromosome break by homologous recombination: revisiting Robin Holliday's model," Philosophical Transactions of the Royal Society B, vol. 359, no. 1441, pp. 7986, 2004.

[81] E. K. Schwartz and W. D. Heyer, "Processing of joint molecule intermediates by structure-selective endonucleases during homologous recombination in eukaryotes," Chromosoma, vol. 120, no. 2, pp. 109-127, 2011.
[82] S. C. West, "Processing of recombination intermediates by the RuvABC proteins," Annual Review of Genetics, vol. 31, pp. 213-244, 1997.

[83] M. N. Boddy, P. H. Gaillard, W. H. McDonald, P. Shanahan, J. R. Yates III, and P. Russell, "Mus81-Eme1 are essential components of a Holliday junction resolvase," Cell, vol. 107, no. 4, pp. 537-548, 2001.

[84] S. Fekairi, S. Scaglione, C. Chahwan et al., "Human SLX4 Is a holliday junction resolvase subunit that binds multiple DNA repair/recombination endonucleases," Cell, vol. 138, no. 1, pp. 78-89, 2009.

[85] J. M. Svendsen, A. Smogorzewska, M. E. Sowa et al., "Mammalian BTBD12/SLX4 assembles a holliday junction resolvase and is required for DNA repair," Cell, vol. 138, no. 1, pp. 63-77, 2009.

[86] S. L. Andersen, D. T. Bergstralh, K. P. Kohl, J. R. LaRocque, C. B. Moore, and J. Sekelsky, "Drosophila MUS312 and the vertebrate ortholog BTBD12 interact with DNA structurespecific endonucleases in DNA repair and recombination," Molecular Cell, vol. 35, no. 1, pp. 128-135, 2009.

[87] A. Z. Al-minawi, N. Saleh-gohari, and T. Helleday, "The ERCC1/XPF endonuclease is required for efficient singlestrand annealing and gene conversion in mammalian cells," Nucleic Acids Research, vol. 36, no. 1, pp. 1-9, 2008.

[88] S. C. Ip, U. Rass, M. G. Blanco, H. R. Flynn, J. M. Skehel, and S. C. West, "Identification of Holliday junction resolvases from humans and yeast," Nature, vol. 456, no. 7220, pp. 357$361,2008$.

[89] J. M. Svendsen and J. W. Harper, "GEN1/Yen1 and the SLX4 complex: solutions to the problem of Holliday junction resolution," Genes and Development, vol. 24, no. 6, pp. 521536, 2010.

[90] K. A. Bernstein, S. Gangloff, and R. Rothstein, “The RecQ DNA helicases in DNA repair," Annual Review of Genetics, vol. 44, pp. 393-417, 2010.

[91] G. Liberi, G. Maffioletti, C. Lucca et al., "Rad51-dependent DNA structures accumulate at damaged replication forks in sgs1 mutants defective in the yeast ortholog of BLM RecQ helicase," Genes and Development, vol. 19, no. 3, pp. 339-350, 2005.

[92] K. Hanada and I. D. Hickson, "Molecular genetics of RecQ helicase disorders," Cellular and Molecular Life Sciences, vol. 64, no. 17, pp. 2306-2322, 2007.

[93] P. R. Prince, M. J. Emond, and R. J. Monnat Jr., "Loss of werner syndrome protein function promotes aberrant mitotic recombination," Genes and Development, vol. 15, no. 8, pp. 933-938, 2001.

[94] Y. Saintigny, K. Makienko, C. Swanson, M. J. Emond, and R. J. Monnat Jr., "Homologous recombination resolution defect in Werner syndrome," Molecular and Cellular Biology, vol. 22, no. 20, pp. 6971-6978, 2002.

[95] M. Payne and I. D. Hickson, "Genomic instability and cancer: lessons from analysis of Bloom's syndrome," Biochemical Society Transactions, vol. 37, no. 3, pp. 553-559, 2009.

[96] A. Constantinou, M. Tarsounas, J. K. Karow et al., "Werner's syndrome protein (WRN) migrates Holliday junctions and co-localizes with RPA upon replication arrest," $E M B O$ Reports, vol. 1, no. 1, pp. 80-84, 2000.

[97] J. K. Karow, A. Constantinou, J. L. Li, S. C. West, and I. D. Hickson, "The Bloom's syndrome gene product promotes branch migration of Holliday junctions," Proceedings of the National Academy of Sciences of the United States of America, vol. 97, no. 12, pp. 6504-6508, 2000. 
[98] R. J. Bennett, J. L. Keck, and J. C. Wang, "Binding specificity determines polarity of DNA unwinding by the Sgs1 protein of S. cerevisiae," Journal of Molecular Biology, vol. 289, no. 2, pp. 235-248, 1999.

[99] F. G. Harmon and S. C. Kowalczykowski, "RecQ helicase, in concert with RecA and SSB proteins, initiates and disrupts DNA recombination," Genes and Development, vol. 12, no. 8, pp. 1134-1144, 1998.

[100] D. V. Bugreev, R. M. Brosh Jr., and A. V. Mazin, "RECQ1 possesses DNA branch migration activity," Journal of Biological Chemistry, vol. 283, no. 29, pp. 20231-20242, 2008.

[101] P. Xie, "Model for RuvAB-mediated branch migration of Holliday junctions," Journal of Theoretical Biology, vol. 249, no. 3, pp. 566-573, 2007.

[102] A. Vindigni, F. Marino, and O. Gileadi, "Probing the structural basis of RecQ helicase function," Biophysical Chemistry, vol. 149, no. 3, pp. 67-77, 2010.

[103] S. A. Compton, G. Tolun, A. S. Kamath-Loeb, L. A. Loeb, and J. D. Griffith, "The Werner syndrome protein binds replication fork and Holliday junction DNAs as an oligomer," Journal of Biological Chemistry, vol. 283, no. 36, pp. 2447824483, 2008.

[104] J. K. Karow, R. H. Newman, P. S. Freemont, and I. D. Hickson, "Oligomeric ring structure of the Bloom's syndrome helicase," Current Biology, vol. 9, no. 11, pp. 597-600, 1999.

[105] V. Popuri, C. Z. Bachrati, L. Muzzolini et al., "The human RecQ helicases, BLM and RECQ1, display distinct DNA substrate specificities," Journal of Biological Chemistry, vol. 283, no. 26, pp. 17766-17776, 2008.

[106] Y. Liu, R. Prasad, W. A. Beard et al., "Coordination between polymerase $\beta$ and FEN1 can modulate CAG repeat expansion," Journal of Biological Chemistry, vol. 284, no. 41, pp. 28352-28366, 2009.

[107] P. Singh, L. Zheng, V. Chavez, J. Qiu, and B. Shen, "Concerted action of exonuclease and gap-dependent endonuclease activities of FEN-1 contributes to the resolution of triplet repeat sequences $(\mathrm{CTG})_{n^{-}}$and $(\mathrm{GAA})_{n}$-derived secondary structures formed during maturation of Okazaki fragments," Journal of Biological Chemistry, vol. 282, no. 6, pp. 34653477, 2007.

[108] R. M. Brosh Jr., C. von Kobbe, J. A. Sommers et al., "Werner syndrome protein interacts with human flap endonuclease 1 and stimulates its cleavage activity," EMBO Journal, vol. 20, no. 20, pp. 5791-5801, 2001.

[109] S. Sharma, J. A. Sommers, L. Wu, V. A. Bohr, I. D. Hickson, and R. M. Brosh, "Stimulation of flap endonuclease-1 by the Bloom's syndrome protein," Journal of Biological Chemistry, vol. 279, no. 11, pp. 9847-9856, 2004.

[110] S. Sharma, M. Otterlei, J. A. Sommers et al., "WRN helicase and FEN-1 form a complex upon replication arrest and together process branch-migrating DNA structures associated with the replication fork," Molecular Biology of the Cell, vol. 15, no. 2, pp. 734-750, 2004.

[111] S. Sharma, J. A. Sommers, and R. M. Brosh Jr., "Processing of DNA replication and repair intermediates by the concerted action of RecQ helicases and Rad2 structure-specific nucleases," Protein and Peptide Letters, vol. 15, no. 1, pp. 89-102, 2008.

[112] S. Sharma, J. A. Sommers, R. K. Gary, E. Friedrich-Heineken, U. Hübscher, and R. M. Brosh Jr., "The interaction site of Flap Endonuclease-1 with WRN helicase suggests a coordination of WRN and PCNA," Nucleic Acids Research, vol. 33, no. 21, pp. 6769-6781, 2005.
[113] S. Sharma, J. A. Sommers, and R. M. Brosh Jr., "In vivo function of the conserved non-catalytic domain of Werner syndrome helicase in DNA replication," Human Molecular Genetics, vol. 13, no. 19, pp. 2247-2261, 2004.

[114] O. Imamura and J. L. Campbell, "The human Bloom syndrome gene suppresses the DNA replication and repair defects of yeast dna2 mutants," Proceedings of the National Academy of Sciences of the United States of America, vol. 100, no. 14, pp. 8193-8198, 2003.

[115] J. D. Bartos, W. Wang, J. E. Pike, and R. A. Bambara, "Mechanisms by which bloom protein can disrupt recombination intermediates of Okazaki fragment maturation," Journal of Biological Chemistry, vol. 281, no. 43, pp. 32227-32239, 2006.

[116] W. Wang and R. A. Bambara, "Human bloom protein stimulates flap endonuclease 1 activity by resolving DNA secondary structure," Journal of Biological Chemistry, vol. 280, no. 7, pp. 5391-5399, 2005.

[117] K. A. Hoadley, D. Xu, Y. Xue, K. A. Satyshur, W. Wang, and J. L. Keck, "Structure and cellular roles of the RMI core complex from the bloom syndrome dissolvasome," Structure, vol. 18, no. 9, pp. 1149-1158, 2010.

[118] L. Wu and I. D. Hickson, “The Bloom's syndrome helicase suppresses crossing over during homologous recombination," Nature, vol. 426, no. 6968, pp. 870-874, 2003.

[119] G. Ira, A. Malkova, G. Liberi, M. Foiani, and J. E. Haber, "Srs2 and Sgs1-Top3 suppress crossovers during doublestrand break repair in yeast," Cell, vol. 115, no. 4, pp. 401411, 2003.

[120] A. Schwacha and N. Kleckner, "Identification of double Holliday junctions as intermediates in meiotic recombination," Cell, vol. 83, no. 5, pp. 783-791, 1995.

[121] M. Bzymek, N. H. Thayer, S. D. Oh, N. Kleckner, and N. Hunter, "Double holliday junctions are intermediates of DNA break repair," Nature, vol. 464, no. 7290, pp. 937-941, 2010.

[122] D. Johnson-Schlitz and W. R. Engels, “Template disruptions and failure of double Holliday junction dissolution during double-strand break repair in Drosophila BLM mutants," Proceedings of the National Academy of Sciences of the United States of America, vol. 103, no. 45, pp. 16840-16845, 2006.

[123] S. Raynard, W. Bussen, and P. Sung, "A double holliday junction dissolvasome comprising BLM, topoisomerase III $\alpha$, and BLAP75," Journal of Biological Chemistry, vol. 281, no. 20, pp. 13861-13864, 2006.

[124] L. Wu, C. Z. Bachrati, J. Ou et al., "BLAP75/RMI1 promotes the BLM-dependent dissolution of homologous recombination intermediates," Proceedings of the National Academy of Sciences of the United States of America, vol. 103, no. 11, pp. 4068-4073, 2006.

[125] W. Bussen, S. Raynard, V. Busygina, A. K. Singh, and P. Sung, "Holliday junction processing activity of the BLM-Topo III $\alpha$ BLAP75 complex," Journal of Biological Chemistry, vol. 282, no. 43, pp. 31484-31492, 2007.

[126] P. Cejka, J. L. Plank, C. Z. Bachrati, I. D. Hickson, and S. C. Kowalczykowski, "Rmil stimulates decatenation of double Holliday junctions during dissolution by Sgs1-Top3," Nature Structural and Molecular Biology, vol. 17, no. 11, pp. 13771382, 2010.

[127] H. W. Mankouri, T. M. Ashton, and I. D. Hickson, "Holliday junction-containing DNA structures persist in cells lacking Sgs1 or Top3 following exposure to DNA damage," Proceedings of the National Academy of Sciences of the United States of America, vol. 108, no. 12, pp. 4944-4949, 2011. 
[128] M. D. Frank-Kamenetskii and S. M. Mirkin, "Triplex DNA structures," Annual Review of Biochemistry, vol. 64, pp. 6595, 1995.

[129] A. Jain, G. Wang, and K. M. Vasquez, "DNA triple helices: biological consequences and therapeutic potential," Biochimie, vol. 90, no. 8, pp. 1117-1130, 2008.

[130] R. Zain and J. S. Sun, "Do natural DNA triple-helical structures occur and function in vivo?" Cellular and Molecular Life Sciences, vol. 60, no. 5, pp. 862-870, 2003.

[131] L. D. Nelson, M. Musso, and M. W. van Dyke, "The yeast STM1 gene encodes a purine motif triple helical DNAbinding protein," Journal of Biological Chemistry, vol. 275, no. 8, pp. 5573-5581, 2000.

[132] M. Musso, G. Bianchi-Scarrà, and M. W. van Dyke, "The yeast CDP1 gene encodes a triple-helical DNA-binding protein," Nucleic Acids Research, vol. 28, no. 21, pp. 40904096, 2000.

[133] I. García-Bassets, M. Ortiz-Lombardía, S. Pagans et al., "The identification of nuclear proteins that bind the homopyrimidine strand of $\mathrm{d}(\mathrm{GATC})_{\mathrm{n}}$ DNA sequences, but not the homopurine strand," Nucleic Acids Research, vol. 27, no. 16, pp. 3267-3275, 1999.

[134] J. S. Lee, G. D. Burkholder, L. J. Latimer, B. L. Haug, and R. P. Braun, "A monoclonal antibody to triplex DNA binds to eucaryotic chromosomes," Nucleic Acids Research, vol. 15, no. 3, pp. 1047-1061, 1987.

[135] S. C. Raghavan, P. Chastain, J. S. Lee et al., "Evidence for a triplex DNA conformation at the bcl-2 major breakpoint region of the $\mathrm{t}(14 ; 18)$ translocation," Journal of Biological Chemistry, vol. 280, no. 24, pp. 22749-22760, 2005.

[136] M. Ohno, T. Fukagawa, J. S. Lee, and T. Ikemura, "Triplexforming DNAs in the human interphase nucleus visualized in situ by polypurine/polypyrimidine DNA probes and antitriplex antibodies," Chromosoma, vol. 111, no. 3, pp. 201213, 2002.

[137] S. M. Mirkin and M. D. Frank-Kamenetskii, "H-DNA and related structures," Annual Review of Biophysics and Biomolecular Structure, vol. 23, pp. 541-576, 1994.

[138] S. C. Raghavan, A. Tsai, C. L. Hsieh, and M. R. Lieber, "Analysis of non-B DNA structure at chromosomal sites in the mammalian genome," Methods in Enzymology, vol. 409, pp. 301-316, 2006.

[139] M. M. Seidman and P. M. Glazer, "The potential for gene repair via triple helix formation," Journal of Clinical Investigation, vol. 112, no. 4, pp. 487-494, 2003.

[140] S. S. Gaddis, Q. Wu, H. D. Thames et al., "A web-based search engine for triplex-forming oligonucleotide target sequences," Oligonucleotides, vol. 16, no. 2, pp. 196-201, 2006.

[141] G. P. Schroth and P. S. Ho, "Occurrence of potential cruciform and H-DNA forming sequences in genomic DNA," Nucleic Acids Research, vol. 23, no. 11, pp. 1977-1983, 1995.

[142] A. Bacolla, J. R. Collins, B. Gold et al., "Long homopurine-homopyrimidine sequences are characteristic of genes expressed in brain and the pseudoautosomal region," Nucleic Acids Research, vol. 34, no. 9, pp. 2663-2675, 2006.

[143] C. Mayfield, S. Ebbinghaus, J. Gee et al., "Triplex formation by the human Ha-ras promoter inhibits Spl binding and in vitro transcription," Journal of Biological Chemistry, vol. 269, no. 27, pp. 18232-18238, 1994.

[144] B. P. Belotserkovskii, E. de Silva, S. Tornaletti, G. Wang, K. M. Vasquez, and P. C. Hanawalt, "A triplex-forming sequence from the human c-MYC promoter interferes with DNA transcription," Journal of Biological Chemistry, vol. 282, no. 44, pp. 32433-32441, 2007.

[145] A. M. Gacy, G. M. Goellner, C. Spiro et al., "GAA instability in Friedreich's Ataxia shares a common, DNA-directed and intraallelic mechanism with other trinucleotide diseases," Molecular Cell, vol. 1, no. 4, pp. 583-593, 1998.

[146] K. Ohshima, L. Montermini, R. D. Wells, and M. Pandolfo, "Inhibitory effects of expanded GAA-TTC triplet repeats from intron I of the Friedreich ataxia gene on transcription and replication in vivo," Journal of Biological Chemistry, vol. 273, no. 23, pp. 14588-14595, 1998.

[147] M. M. Krasilnikova and S. M. Mirkin, "Replication stalling at Friedreich's ataxia (GAA)n repeats in vivo," Molecular and Cellular Biology, vol. 24, no. 6, pp. 2286-2295, 2004.

[148] H. P. Patel, L. Lu, R. T. Blaszak, and J. J. Bissler, "PKD1 intron 21: triplex DNA formation and effect on replication," Nucleic Acids Research, vol. 32, no. 4, pp. 1460-1468, 2004.

[149] G. Wang, S. Carbajal, J. Vijg, J. DiGiovanni, and K. M. Vasquez, "DNA structure-induced genomic instability in vivo," Journal of the National Cancer Institute, vol. 100, no. 24, pp. 1815-1817, 2008.

[150] B. P. Dixon, L. Lu, A. Chu, and J. J. Bissler, "RecQ and RecG helicases have distinct roles in maintaining the stability of polypurine-polypyrimidine sequences," Mutation Research, vol. 643, no. 1-2, pp. 20-28, 2008.

[151] R. M. Brosh Jr., A. Majumdar, S. Desai, I. D. Hickson, V. A. Bohr, and M. M. Seidman, "Unwinding of a DNA triple helix by the Werner and Bloom syndrome helicases," Journal of Biological Chemistry, vol. 276, no. 5, pp. 3024-3030, 2001.

[152] A. Machwe, L. Xiao, J. Groden, and D. K. Orren, “The Werner and Bloom syndrome proteins catalyze regression of a model replication fork," Biochemistry, vol. 45, no. 47, pp. 1393913946, 2006.

[153] A. Jain, A. Bacolla, P. Chakraborty, F. Grosse, and K. M. Vasquez, "Human DHX9 helicase unwinds triple-helical DNA structures," Biochemistry, vol. 49, no. 33, pp. 69926999, 2010.

[154] J. A. Sommers, N. Rawtani, R. Gupta et al., "FANCJ uses its motor ATPase to destabilize protein-DNA complexes, unwind triplexes, and inhibit RAD51 strand exchange," Journal of Biological Chemistry, vol. 284, no. 12, pp. 75057517, 2009.

[155] R. Gupta, S. Sharma, J. A. Sommers, Z. Jin, S. B. Cantor, and R. M. Brosh Jr., "Analysis of the DNA substrate specificity of the human BACH1 helicase associated with breast cancer," Journal of Biological Chemistry, vol. 280, no. 27, pp. 2545025460, 2005.

[156] Y. Wu, S.-Y. Kazuo, and R. M. Brosh Jr., "FANCJ helicase defective in Fanconia anemia and breast cancer unwinds Gquadruplex DNA to defend genomic stability," Molecular and Cellular Biology, vol. 28, no. 12, pp. 4116-4128, 2008.

[157] M. Uhring and A. Poterszman, "DNA helicases and human diseases," Medecine/Sciences, vol. 22, no. 12, pp. 1087-1094, 2006.

[158] C. G. Lee, V. da Costa Soares, C. Newberger, K. Manova, E. Lacy, and J. Hurwitz, "RNA helicase A is essential for normal gastrulation," Proceedings of the National Academy of Sciences of the United States of America, vol. 95, no. 23, pp. 1370913713, 1998.

[159] S. M. Mirkin, "Discovery of alternative DNA structures: a heroic decade (1979-1989)," Frontiers in Bioscience, vol. 13, no. 3, pp. 1064-1071, 2008. 
[160] R. I. Mathad and D. Yang, "G-quadruplex structures and Gquadruplex-interactive compounds," Methods in Molecular Biology, vol. 735, pp. 77-96, 2011.

[161] S. Burge, G. N. Parkinson, P. Hazel, A. K. Todd, and S. Neidle, "Quadruplex DNA: sequence, topology and structure," Nucleic Acids Research, vol. 34, no. 19, pp. 5402-5415, 2006.

[162] J. Zhou, G. Yuan, J. Liu, and C. G. Zhan, "Formation and stability of G-quadruplexes self-assembled from guaninerich strands," Chemistry, vol. 13, no. 3, pp. 945-949, 2007.

[163] A. K. Todd, M. Johnston, and S. Neidle, "Highly prevalent putative quadruplex sequence motifs in human DNA," Nucleic Acids Research, vol. 33, no. 9, pp. 2901-2907, 2005.

[164] J. L. Huppert and S. Balasubramanian, "Prevalence of quadruplexes in the human genome," Nucleic Acids Research, vol. 33, no. 9, pp. 2908-2916, 2005.

[165] H. J. Lipps and D. Rhodes, "G-quadruplex structures: in vivo evidence and function," Trends in Cell Biology, vol. 19, no. 8, pp. 414-422, 2009.

[166] M. L. Duquette, P. Handa, J. A. Vincent, A. F. Taylor, and N. Maizels, "Intracellular transcription of G-rich DNAs induces formation of G-loops, novel structures containing G4 DNA," Genes and Development, vol. 18, no. 13, pp. 1618-1629, 2004.

[167] K. Paeschke, T. Simonsson, J. Postberg, D. Rhodes, and H. J. Lipps, "Telomere end-binding proteins control the formation of G-quadruplex DNA structures in vivo," Nature Structural and Molecular Biology, vol. 12, no. 10, pp. 847-854, 2005.

[168] S. G. Hershman, Q. Chen, J. Y. Lee et al., "Genomic distribution and functional analyses of potential G-quadruplexforming sequences in Saccharomyces cerevisiae," Nucleic Acids Research, vol. 36, no. 1, pp. 144-156, 2008.

[169] N. Maizels, "Dynamic roles for G4 DNA in the biology of eukaryotic cells," Nature Structural and Molecular Biology, vol. 13, no. 12, pp. 1055-1059, 2006.

[170] E. Kruisselbrink, V. Guryev, K. Brouwer, D. B. Pontier, E. Cuppen, and M. Tijsterman, "Mutagenic capacity of endogenous G4 DNA underlies genome instability in FANCJdefective C. elegans," Current Biology, vol. 18, no. 12, pp. 900 $905,2008$.

[171] I. Cheung, M. Schertzer, A. Rose, and P. M. Lansdorp, "Disruption of dog-1 in Caenorhabditis elegans triggers deletions upstream of guanine-rich DNA," Nature Genetics, vol. 31, no. 4, pp. 405-409, 2002.

[172] T. B. London, L. J. Barber, G. Mosedale et al., "FANCJ is a structure-specific DNA helicase associated with the maintenance of genomic G/C tracts," Journal of Biological Chemistry, vol. 283, no. 52, pp. 36132-36139, 2008.

[173] H. Ding, M. Schertzer, X. Wu et al., "Regulation of murine telomere length by Rtel: an essential gene encoding a helicaselike protein,” Cell, vol. 117, no. 7, pp. 873-886, 2004.

[174] X. Wu and N. Maizels, "Substrate-specific inhibition of RecQ helicase," Nucleic Acids Research, vol. 29, no. 8, pp. 1765$1771,2001$.

[175] H. Sun, R. J. Bennett, and N. Maizels, “The Saccharomyces cerevisiae Sgs1 helicase efficiently unwinds G-G paired DNAs," Nucleic Acids Research, vol. 27, no. 9, pp. 1978-1984, 1999.

[176] M. Fry and L. A. Loeb, "Human Werner syndrome DNA helicase unwinds tetrahelical structures of the fragile $\mathrm{X}$ syndrome repeat sequence d(CGG) ", Journal of Biological Chemistry, vol. 274, no. 18, pp. 12797-12802, 1999.

[177] H. Sun, J. K. Karow, I. D. Hickson, and N. Maizels, "The Bloom's syndrome helicase unwinds G4 DNA," Journal of Biological Chemistry, vol. 273, no. 42, pp. 27587-27592, 1998.
[178] M. D. Huber, D. C. Lee, and N. Maizels, "G4 DNA unwinding by BLM and Sgslp: substrate specificity and substratespecific inhibition," Nucleic Acids Research, vol. 30, no. 18, pp. 3954-3961, 2002.

[179] P. Mohaghegh, J. K. Karow, R. M. Brosh Jr., V. A. Bohr, and I. D. Hickson, "The Bloom's and Werner's syndrome proteins are DNA structure-specific helicases," Nucleic Acids Research, vol. 29, no. 13, pp. 2843-2849, 2001.

[180] H. Cohen and D. A. Sinclair, "Recombination-mediated lengthening of terminal telomeric repeats requires the Sgs1 DNA helicase," Proceedings of the National Academy of Sciences of the United States of America, vol. 98, no. 6, pp. 3174-3179, 2001.

[181] P. H. Huang, F. E. Pryde, D. Lester et al., "SGS1 is required for telomere elongation in the absence of telomerase," Current Biology, vol. 11, no. 2, pp. 125-129, 2001.

[182] F. B. Johnson, R. A. Marciniak, M. McVey, S. A. Stewart, W. C. Hahn, and L. Guarente, "The Saccharomyces cerevisiae WRN homolog Sgs1p participates in telomere maintenance in cells lacking telomerase," EMBO Journal, vol. 20, no. 4, pp. 905913, 2001.

[183] V. Kaliraman and S. J. Brill, "Role of SGS1 and SLX4 in maintaining rDNA structure in Saccharomyces cerevisiae," Current Genetics, vol. 41, no. 6, pp. 389-400, 2002.

[184] G. Versini, I. Comet, M. Wu, L. Hoopes, E. Schwob, and P. Pasero, "The yeast Sgs1 helicase is differentially required for genomic and ribosomal DNA replication," EMBO Journal, vol. 22, no. 8, pp. 1939-1949, 2003.

[185] R. A. Marciniak, D. B. Lombard, F. B. Johnson, and L. Guarente, "Nucleolar localization of the Werner Syndrome protein in human cells," Proceedings of the National Academy of Sciences of the United States of America, vol. 95, no. 12, pp. 6887-6892, 1998.

[186] S. L. Ding and C. Y. Shen, "Model of human aging: recent findings on Werner's and Hutchinson-Gilford progeria syndromes," Clinical Interventions in Aging, vol. 3, no. 3, pp. 431444, 2008.

[187] L. Crabbe, R. E. Verdun, C. I. Haggblom, and J. Karlseder, "Defective telomere lagging strand synthesis in cells lacking WRN helicase activity," Science, vol. 306, no. 5703, pp. 19511953, 2004.

[188] P. L. Opresko, M. Otterlei, J. Graakjær et al., "The werner syndrome helicase and exonuclease cooperate to resolve telomeric D loops in a manner regulated by TRF1 and TRF2," Molecular Cell, vol. 14, no. 6, pp. 763-774, 2004.

[189] P. L. Opresko, C. von Kobbe, J. P. Laine, J. Harrigan, I. D. Hickson, and V. A. Bohr, "Telomere-binding protein TRF2 binds to and stimulates the Werner and Bloom syndrome helicases," Journal of Biological Chemistry, vol. 277, no. 43, pp. 41110-41119, 2002.

[190] A. S. Kamath-Loeb, L. A. Loeb, E. Johansson, P. M. Burgers, and M. Fry, "Interactions between the Werner Syndrome Helicase and DNA Polymerase $\delta$ Specifically Facilitate Copying of Tetraplex and Hairpin Structures of the $\mathrm{d}(\mathrm{CGG})_{\mathrm{n}}$ Trinucleotide Repeat Sequence," Journal of Biological Chemistry, vol. 276, no. 19, pp. 16439-16446, 2001.

[191] A. S. Kamath-Loeb, E. Johansson, P. M. Burgers, and L. A. Loeb, "Functional interaction between the Werner syndrome protein and DNA polymerase $\delta$," Proceedings of the National Academy of Sciences of the United States of America, vol. 97, no. 9, pp. 4603-4608, 2000.

[192] A. M. Szekely, F. Bleichert, A. Nümann et al., "Werner protein protects nonproliferating cells from oxidative DNA damage," 
Molecular and Cellular Biology, vol. 25, no. 23, pp. 10492 10506, 2005.

[193] N. Selak, C. Z. Bachrati, I. Shevelev et al., "The Bloom's syndrome helicase (BLM) interacts physically and functionally with $\mathrm{p} 12$, the smallest subunit of human DNA polymerase $\delta$," Nucleic Acids Research, vol. 36, no. 16, pp. 5166-5179, 2008.

[194] C. Ribeyre, J. Lopes, J.-B. Boulé et al., "The yeast Pif1 helicase prevents genomic instability caused by G-quadruplexforming CEB1 sequences in vivo," PLoS Genetics, vol. 5, no. 5, Article ID e1000475, 2009.

[195] C. M. Sanders, "Human Pif1 helicase is a G-quadruplex DNA-binding protein with G-quadruplex DNA-unwinding activity," Biochemical Journal, vol. 430, no. 1, pp. 119-128, 2010.

[196] J. B. Boulé, L. R. Vega, and V. A. Zakian, "The yeast Pif1p helicase removes telomerase from telomeric DNA," Nature, vol. 438, no. 7064, pp. 57-61, 2005.

[197] D. H. Zhang, B. Zhou, Y. Huang, L. X. Xu, and J. Q. Zhou, "The human Pif1 helicase, a potential Escherichia coli RecD homologue, inhibits telomerase activity," Nucleic Acids Research, vol. 34, no. 5, pp. 1393-1404, 2006.

[198] K. Paeschke, J. A. Capra, and V. A. Zakian, "DNA replication through g-quadruplex motifs is promoted by the Saccharomyces cerevisiae Pif1 dna helicase," Cell, vol. 145, no. 5, pp. 678-691, 2011.

[199] B. E. Snow, M. Mateyak, J. Paderova et al., "Murine Pif1 interacts with telomerase and is dispensable for telomere function in vivo," Molecular and Cellular Biology, vol. 27, no. 3, pp. 1017-1026, 2007.

[200] S. Sharma, D. J. Stumpo, A. S. Balajee et al., "RECQL, a member of the RecQ family of DNA helicases, suppresses chromosomal instability," Molecular and Cellular Biology, vol. 27, no. 5, pp. 1784-1794, 2007.

[201] J. Déjardin and R. E. Kingston, "Purification of proteins associated with specific genomic Loci," Cell, vol. 136, no. 1, pp. 175-186, 2009.

[202] J. R. Lydeard, Z. Lipkin-Moore, S. Jain, V. V. Eapen, and J. E. Haber, "Sgs1 and exo1 redundantly inhibit breakinduced replication and de novo telomere addition at broken chromosome ends," PLoS Genetics, vol. 6, no. 5, Article ID e1000973, 2010.

[203] K. M. Doherty, S. Sharma, L. A. Uzdilla et al., "RECQ1 helicase interacts with human mismatch repair factors that regulate genetic recombination," Journal of Biological Chemistry, vol. 280, no. 30, pp. 28085-28094, 2005.

[204] W. K. Chu and I. D. Hickson, "RecQ helicases: multifunctional genome caretakers," Nature Reviews Cancer, vol. 9, no. 9, pp. 644-654, 2009.

[205] J.-M. Chen, D. N. Cooper, C. Férec, H. Kehrer-Sawatzki, and G. P. Patrinos, "Genomic rearrangements in inherited disease and cancer," Seminars in Cancer Biology, vol. 20, no. 4, pp. 222-233, 2010.

[206] A. Bacolla, G. Wang, A. Jain et al., "Non-B DNA-forming sequences and WRN deficiency independently increase the frequency of base substitution in human cells," Journal of Biological Chemistry, vol. 286, no. 12, pp. 10017-10026, 2011.

[207] S. Sharma, K. M. Doherty, and R. M. Brosh Jr., "DNA helicases as targets for anti-cancer drugs," Current Medicinal Chemistry, vol. 5, no. 3, pp. 183-199, 2005.

[208] L. A. Christensen, R. A. Finch, A. J. Booker, and K. M. Vasquez, "Targeting oncogenes to improve breast cancer chemotherapy," Cancer Research, vol. 66, no. 8, pp. 4089-4094, 2006.
[209] S. Balasubramanian, L. H. Hurley, and S. Neidle, "Targeting G-quadruplexes in gene promoters: a novel anticancer strategy?" Nature Reviews Drug Discovery, vol. 10, no. 4, pp. 261-275, 2011.

[210] M. Aggarwal, J. A. Sommers, R. H. Shoemaker, and R. M. Brosh Jr., "Inhibition of helicase activity by a small molecule impairs Werner syndrome helicase (WRN) function in the cellular response to DNA damage or replication stress," Proceedings of the National Academy of Sciences of the United States of America, vol. 108, no. 4, pp. 1525-1530, 2011. 

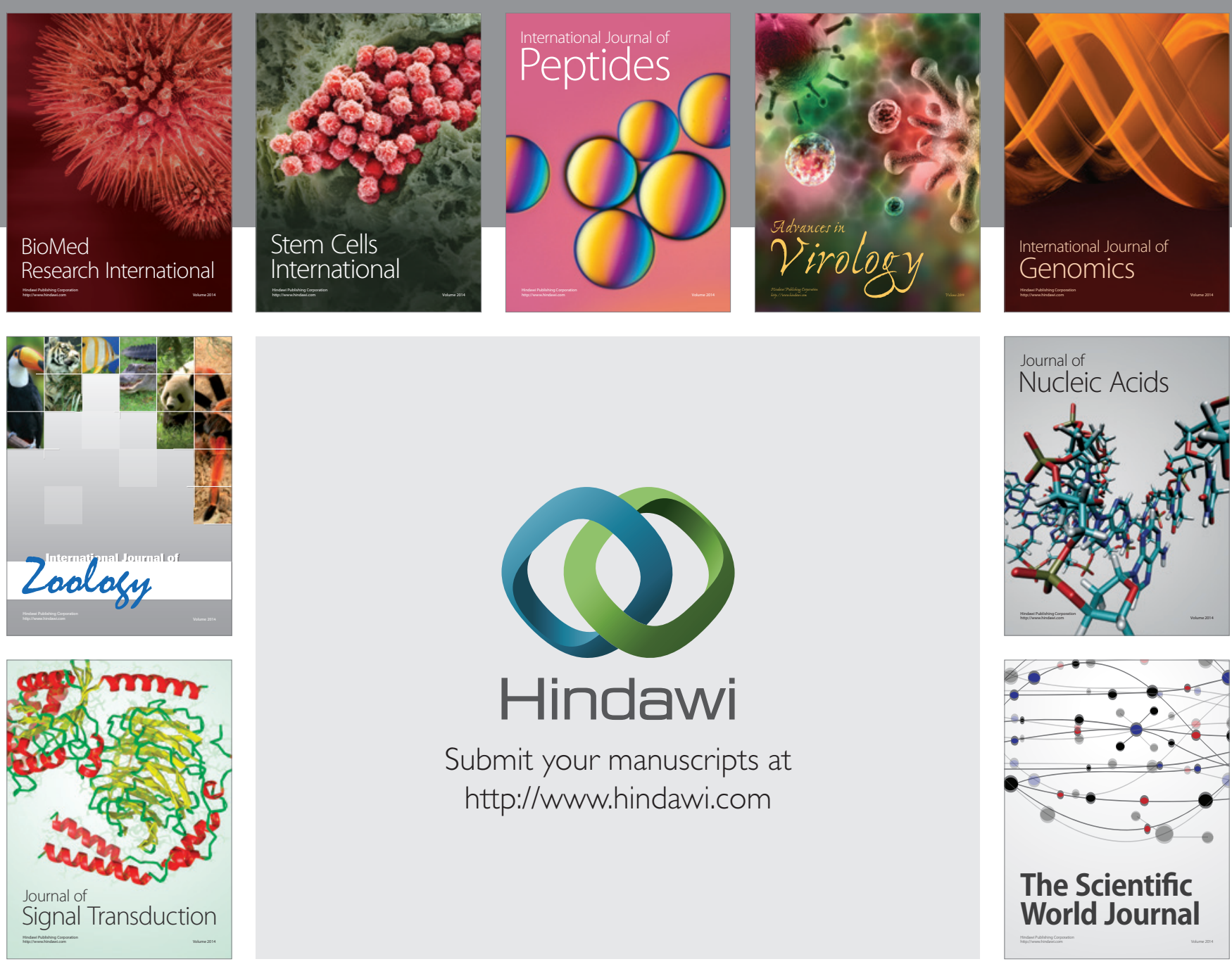

Submit your manuscripts at

http://www.hindawi.com
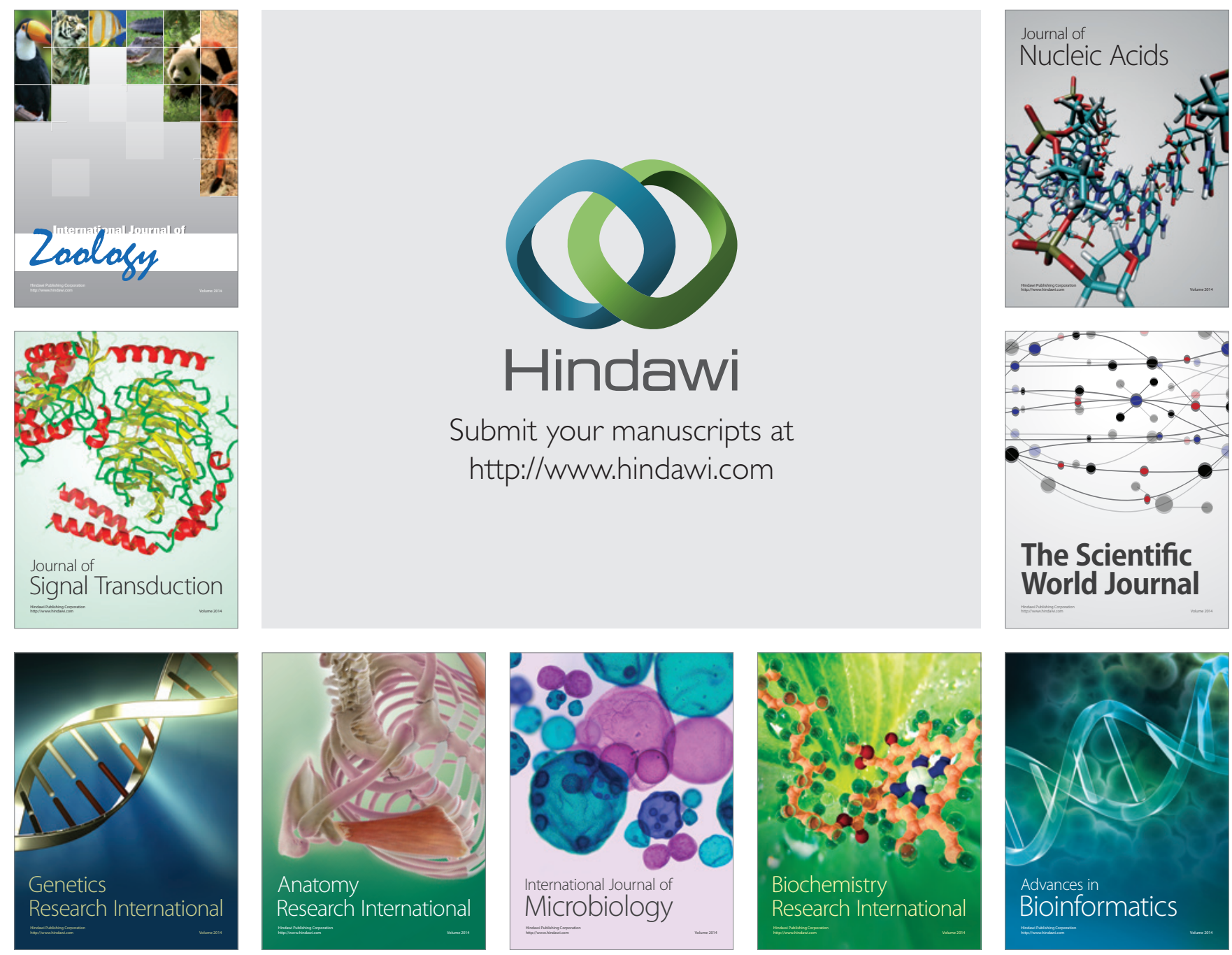

The Scientific World Journal
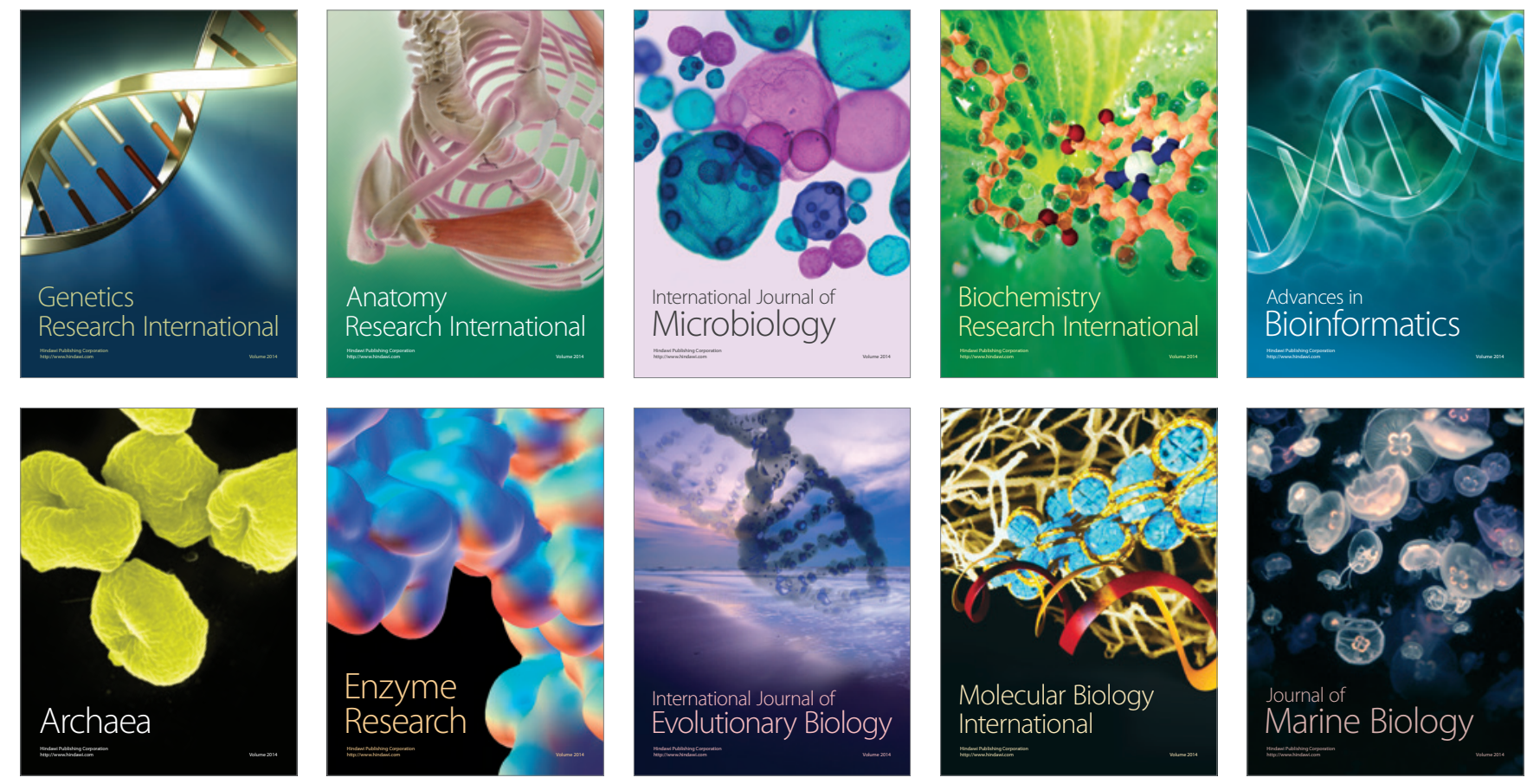